\title{
Forward-looking asset correlations in the estimation of economic capital
}

Instituto

Complutense

de Análisis

Económico

\section{Álvaro Chamizo}

BBVA.

\section{Alexandre Fonollosa}

BBVA.

\section{Alfonso Novales}

Instituto Complutense de Análisis Económico (ICAE), and

Department of Economic Analysis, Facultad de Ciencias Económicas y Empresariales, Universidad Complutense, 28223 Madrid, Spain

\begin{abstract}
Weanalyze whether the credit market anticipated the financial crisis before the regulators using a methodology that combines the Merton model for the determination of economic capital with Vasicek's factor model for asset correlation. Contrary to standard practice, we estimate the credit value at risk (VaR) and expected shortfall (ES) of a global loan portfolio using CDS spreads because credit derivat- ives incorporate forward-looking information on future systemic shocks that might be essential in the estimation of economic capital. We find that one-factor model can generally be a good representation of correlations in the credit market because of the high intersector correlations, although an appro- priately chosen second factor can provide additional information for risk estimation in stressed times. We show that there were, indeed, signs of stress in the credit market that were not incorporated in the determination of economic capital during the crisis and that some financial institutions did not con- sider properly. The overall impression is that it is not so much that risk models were over-simplified to anticipate the financial crisis but rather, that they were backward-looking. A potential implication of our research is that the level of regulatory capital should react to events in the credit market.
\end{abstract}

Keywords Forward-looking Asset Correlation, Economic Capital, Asset Allocation, Systemic Risk.

JEL classification: E47, G01, G28, G32

\section{Working Paper no 1925 \\ September, 2019}




\title{
Forward-looking asset correlations in the estimation of economic capital
}

\author{
Authors: \\ Álvaro Chamizo ${ }^{1}$, \\ Alexandre Fonollosa ${ }^{2},{ }^{3}$ \\ Alfonso Novales ${ }^{4}, 5$
}

\begin{abstract}
We analyze whether the credit market anticipated the financial crisis before the regulators using a methodology that combines the Merton model for the determination of economic capital with Vasicek's factor model for asset correlation. Contrary to standard practice, we estimate the credit value at risk (VaR) and expected shortfall (ES) of a global loan portfolio using CDS spreads because credit derivatives incorporate forward-looking information on future systemic shocks that might be essential in the estimation of economic capital. We find that one-factor model can generally be a good representation of correlations in the credit market because of the high inter-sector correlations, although an appropriately chosen second factor can provide additional information for risk estimation in stressed times. We show that there were, indeed, signs of stress in the credit market that were not incorporated in the determination of economic capital during the crisis and that some financial institutions did not consider properly. The overall impression is that it is not so much that risk models were over-simplified to anticipate the financial crisis but rather, that they were backward-looking. A potential implication of our research is that the level of regulatory capital should react to events in the credit market.
\end{abstract}

JEL classification: E47, G01, G28, G32

Keywords: Forward-looking Asset Correlation, Economic Capital, Asset Allocation, Systemic Risk.

\section{Motivation}

The most popular approach to determining the economic capital needed for a loan portfolio is the Merton (1974) 'structural' model. Its principal advantage is its strong economic rationale, which explains the default of a firm when the value of its assets falls below the value of its debt. This is the ap-

\footnotetext{
${ }^{1}$ Álvaro Chamizo: BBVA. e-mail: alvaro.chamizo@bbva.com.

${ }^{2}$ Alexandre Fonollosa: BBVA. e-mail: alexandre.fonollosa@bbva.com.

${ }^{3}$ This article reflects the opinions of the authors, but not the opinion of BBVA.

${ }^{4}$ Alfonso Novales, Instituto Complutense de Análisis Económico (ICAE) and Departamento de Análisis Económico, Facultad de Ciencias Económicas y Empresariales, Campus de Somosaguas, Universidad Complutense (28223 Madrid). Financial support by grants ECO2015-67305-P, PrometeoII/2013/015, Programa de Ayudas a la Investigación from Banco de España is gratefully acknowledged.

${ }^{5}$ The authors acknowledge comments received from C. Matres Santos.
} 
proach followed in the Basel II IRB (Internal Ratings-Based) model to calculate the level of economic capital for those institutions that use advanced risk models. The correlations among the value of assets from different firms are the central input for the calculation of the level of capital needed to face unexpected losses in a loan portfolio [see Basel BCBS (2006)]. Unfortunately, asset correlations are not directly observable in the market and different methods have been proposed for their estimation by McGinty et al. (2004). In the Basel II model, the correlation across firms is specified as a deterministic function of the probability of default. With a dataset for 1998-2004, Dullmann et al. (2007) departed from the Basel II assumption on asset correlation but his results, using various model specifications for asset correlation, were similar to those from the Basel II IRB approach. The main reason for that coincidence might be that the Basel II IRB model was calibrated to the KMV database, which is also used by Dullmann et al. (2007) for a very similar time frame [see Crosbie (1999) and Crosbie (2003) for more details].

Alternatively, we propose a practical strategy that allows us to estimate economic capital using the forward-looking information on the market perception of risk contained in CDS spread data. We perform an analysis similar to Dullmann, in our case using CDS data, with eleven industries instead of the six industries used by Dullmann, and for a more recent period, 2006-2012, so that we can distinguish among the pre-crisis, global crisis, and post-crisis periods. The implied estimates of economic capital might provide us with relevant information about future systemic adverse shocks, besides being a useful tool for risk management and asset allocation. The idea is to place our estimates in the context of regulatory capital requirement by comparison with the Basel II regulation. ${ }^{6}$ We want to explore whether there was some anticipation in the credit market of the upcoming crisis that financial institutions and regulators ignored. This is related to the deeper question of how the regulation on capital should react to events in the credit market, because the loan portfolio of financial institutions is generally valued at historical prices, with a very small sensitivity to the CDS market. Finally, we also hope to get some insight into what would be the impact on economic capital of using CDS spreads to mark a loan portfolio to the market.

We estimate the value at risk (VaR) and expected shortfall (ES) for a global credit portfolio by simulating the occurrence of default across the universe of firms. We consider an equally weighted portfolio made up of CDS contracts from each of a set of 881 issuers. In the first structural model of default for a single firm proposed by Merton (1974), default arises when the value of a given firm falls below the value of its assets. Black and Cox (1976) provided an important extension of Merton's model. Their model has a first passage time structure where a default takes place whenever the value of the assets of a company drops below a barrier level. This model was calibrated by Jacobs (2011). Extending the model in the context of a single firm has been the object of a large strand of academic literature. Zhou (2001) and Hull and White (2001) were the first to incorporate default correlation between different is-

\footnotetext{
${ }^{6}$ Moreover, for the purpose of regulatory capital the use of more stable inputs like PDs and LGDs may help to avoid an excessive volatility in profitability metrics.
} 
suers into the Black and Cox first passage time structural model. The characterization of joint default probabilities in Zhou (2001) can just be used for two firms. Hull and White (2001) consider an arbitrary number of firms, but their model is computationally time-consuming. Hull et al. (2010) solve those limitations by providing a way to model default correlation using the Black-Cox structural model framework. They assume that the value of assets of any given firm follows a geometric Brownian motion, and calibrate the first passage time model to market data. Then, a one-factor Vasicek correlation model is used to represent the joint correlation between $\mathrm{N}$ firms. A similar analysis is also performed by Tarashev and Zhu (2008).

We use the first passage time structure by Hull et al. (2010) to estimate default probabilities for each firm in the portfolio, and we use four alternative specifications of Vasicek-type factor correlation models to estimate asset correlations. Having a good representation of the correlation among the value of assets for the different firms in the credit portfolio through their dependence on common risk factors is crucial for VaR, ES and economic capital estimation. We start by estimating a Modified Distance to Default (MDD) for each firm and each period using CDS spread data. Correlations between MDD estimates obtained from rolling window samples are then used to calibrate the alternative correlation models. They are simulated for each firm throughout the 2006-2012 sample, and the occurrence of default is evaluated by comparing the change in the value of assets with the threshold consistent with the probability of default associated by Moody's to each rating grade. By simulating a large number of trajectories, we have an empirical distribution of default events for each firm and time period. In case of default, we compute the loss as (1-R)\% of the exposure to that firm, with $\mathrm{R}$ being the recovery rate, and we aggregate losses across the portfolio. The level of VaR is estimated each period as the desired percentile of the distribution of porfolio P\&L, and ES is estimated by integrating over the tail. Weekly data on recovery rates are taken from Markit. Even though we perform our analysis for a global portfolio, the model is simulated for each single firm in the sample, so that our methodology could easily be applied to estimate the VaR and ES of specific portfolios.

The results of our analysis suggest a significant underestimation of capital over the financial crisis. There were clear signs of stress in the credit market prior to the crisis that were not appropriately taken into account by some financial institutions, and that regulators did not take into account when determining capital requirements. The increased correlation in the credit market seems to have been mainly responsible for the increase in value at risk during the financial crisis, with the increase in the physical probability of default playing a secondary role. These results are robust to the specification used for asset correlation, as well as to different modelling choices that we analyze below. They also arise working with corporate bond data, although we suggest a preference for CDS data because of their relative simplicity, in spite of the recent shrinking of the CDS market. ${ }^{7}$ The general time evolution

\footnotetext{
${ }^{7}$ Working with bond data requires choosing a particular yield curve as reference as well as assuming that bond payments are compensation for credit risk, ignoring other components like a possible liquidity premium. Choosing a representative bond from the set of bonds outstanding at a given point in time for the same issuer is an added complexity that does not arise with CDS data.
} 
of value at risk estimates obtained from credit and bond data is broadly similar, although there are also noticeable differences at some specific points in time that deserve to be the object of future research.

Section 2 contains a description of our dataset, while the correlation models are presented in Section 3. In Section 4 we detail the results from VaR estimation, and we relate our results to the different stages of the financial crisis. In section 5 we compute estimates of Expected Shortfall. In section 6 we analyze the results obtained with corporate bond data. To validate our models, in Section 7 we examine whether our results are in line with rating agencies. In Section 8 we present the results obtained with a two-systemic risk factor model. Implications for regulatory credit risk modelling are discussed in Section 9. We close with the main conclusions and open questions in Section 10.

\section{Description of the Data}

We have used the database provided by Markit, the main supplier of CDS prices [see Markit (2008) and Markit (2012)]. We selected the fields: ticker, tier, spread, sector and region. The ticker gives information on the key name of the issuer. Tier contains the type of debt that is to be delivered in the event of a default. This might be SEDCOM Secured Debt (Corporate/Financial), SNRFOR Senior Unsecured Debt (Corporate/Financial), SOVEREIGN Debt (Government), SUBLT2 Subordinated or Lower Tier 2 Debt (Banks), JRSUBUT2 Junior Subordinated or Upper Tier 2 Debt (Banks), and PREFT1 Preference Shares, or Tier 1 Capital (Banks). Markit provides information on CDS spreads with different tenors: 6M, 1Y, 2Y, 3Y, 4Y, 5Y, 7Y, 10Y, 15Y, 20Y, and 30Y. All these prices are composite; that is, for a given restructuring event, issuer and currency, they are the average of prices provided by different financial institutions. The classification of sectors in the Markit database is based on the ICB (Industry Classification Benchmark), which distinguishes four levels: industry, supra-sector, sector, and subsector. We work at the Markit industry level, which considers eleven industries: basic materials, consumer goods, consumer services, energy, financials, health care, industrials, technology, telecommunication services, utilities, and government (Markit category). Markit also considers thirteen different regions: Africa, Asia, Caribbean, Eastern Europe, Europe, India, Latin America, Middle East, North America, Oceania, Offshore, Pacific and Supranational, but we have not made any geographical distinction in our analysis.

Even though we estimate the one-year ahead probability of default, we use the daily senior 5-year CDS contract with the standard currency and the restructuring clause because of its liquidity and representativeness. ${ }^{8}$ We analyze the period from January 2006 to December 2012, an undoubtedly relevant period of time for the credit market, covering the recent global financial crisis. We have just considered those issuers for which we have a daily price for the senior 5-year CDS contract. These filters leave us with a sample of 881 issuers, most of them located in Europe, North America and Asia.

\footnotetext{
${ }^{8}$ Such choice implicitely assumes that the stochastic structure of returns allows for time aggregation
} 
Table 1 summarizes information on the issuers by industry, region, and industry/region. As interest rate $r$ we take the 5-year swap rate for the reference currency of each CDS issuer: the euro swap rate for Europe, USD rate for America and the yen rate for Japan.

Finally, we have used Moody's database to assign a daily rating to each different issuer over the 2006-2012 period. Extending the sample farther would lead us to lose a number of firms. Since our purpose is to discuss the forward-looking information in the credit market during the crisis, we decided to stop in 2012. ${ }^{9}$ Tables 2 and 3 present the distribution of sector ratings on 30 June 2006 and 30 June 2012, showing a clear deterioration in almost all industries during the 2007-2012 crisis period, with the exceptions of the energy and health care industries. The last column in Table 3 displays the probability of default associated with each rating in Ou et al. (2013). ${ }^{10}$ Using this correspondence between ratings and default probabilities, we present in Figure 10.1 the evolution over time of the sectorial probabilities of default, as the average across firms in each sector. ${ }^{11}$ Default probabilities increased during the crisis period, although in an heterogeneous manner. The probability of default in the financial sector increased considerably during the crisis period, reflecting the fact that it was mainly a global financial crisis, but only after mid-2008, not as much as one would expect a posteriori. The less cyclical sectors, like utilities, energy and basic materials had a lower probability of default, on average. On the contrary, the perception of risk in the more cyclical sectors, like consumer goods or consumer services was highly affected by the global crisis and, in fact, their increase in default probability started somewhat earlier. Other sectors, like healthcare or telecommunications show just a moderate increase in the probability of default, in line with the increase experienced by the default probability for the whole sample of firms. It is remarkable that on December 2012, the increase in the probability of default had not reverted yet to the levels previous to the crisis.

(INSERT HERE TABLES 1, 2, 3 )

(INSERT HERE FIGURE 10.1)

\section{A model of default correlations}

The specification of the full set of joint default probabilities among firms in the sample would be unmanageable. There are $2^{N}$ pair default events for $N$ obligors, which would be impossible to handle even for a relatively low number of counterparties. The problem can be solved by using structural correlation models, which can use alternative sources for assessing default correlation [see Schönbucher (2000)]: i) Actual rating and default events are the most natural source, although they are hardly ever used in practice. Since defaults are very rare events, obtaining a significant number of observations

\footnotetext{
${ }^{9} \mathrm{An}$ analysis with a longer sample, but less firms, is performed later on, when we compare the results provided by CDS data and bond data.

${ }^{10}$ The data is taken from Exhibit 23 in : Annual Credit Loss Rates by Letter Rating, 1982-2012* in Ou et al. (2013)

${ }^{11}$ Changes in PD are mainly due to re-ratings of credit.
} 
on defaults would require a long history and the economic circumstances of a very remote past may not be relevant today, ii) Equity correlations, since it usually claimed that credit and equity are related. That belief is based on Merton (1974) 'structural' model which provided an explicit relationship among default risk and the capital structure of the firm. Hence, equity returns are often used as a proxy for asset returns when using structural models. The advantage of using equity data is that there is a good history of company prices. The main limitation of this approach is that the link between equity, debt, and the value of assets (leverage) is not constant, and it is difficult to measure and judge. For example, two firms can be highly correlated from the point of view of equity returns, and at the same time, exhibit a low asset correlation, iii) Credit spreads provide continuous information on the default risk of traded bonds, although bond prices may be influenced by illiquidity factors. Moreover, a large strand of literature shows that there are diverse determinants of credit spreads, not all of them necessarily linked to default risk [see, among many others, Ericsson et al. (2009), Karagozoglu and Jacobs (2016)]. Also, there is no theoretical justification for a direct link between credit spread correlation and default correlation. For example, Huang and Huang (2012) found that credit risk accounts for only a small fraction of the observed corporate-Treasury yield spreads for investment grade bonds of all maturities, the fraction being still smaller for short maturity bonds, and it accounts for a much higher fraction of yield spreads for junk bonds.

None of these approaches is free of limitations. We will use the concept of Distance to Default as in Merton's model combined with CDS data to derive estimates of default probabilities.

\subsection{Modelling default}

We follow Tarashev and Zhu (2008) to model the cross-sectional interdependence of default events as driven by the correlation of a firm-specific 'default trigger' random variable, which is a one-dimensional summary of credit quality and it is extracted from CDS spreads, as explained below. The default-trigger variable will therefore comprise all the information that is considered relevant and processed in singlename CDS spreads. This is the Z-score methodology that banks use in stress testing to model default correlation in project stressed rating-migration matrices.

As in Tarashev and Zhu (2008), we refer to the default-trigger variable as 'the value of firm's assets' and incorporate it into a Merton-type model of the firm. ${ }^{12}$ We start by assuming that the asset value of any given firm $i$ follows a geometric Brownian motion as:

$$
d V_{i, t}=\mu_{i} V_{i, t} d t+\sigma_{i} V_{i, t} d W_{i, t}, i=1,2, \ldots n
$$

\footnotetext{
${ }^{12}$ Merton's model has been extensively used in the credit risk literature. As a recent example, Erlenmaier and Gersbach (2013) use it to show the association between default correlations and default probabilities.
} 
Where $\mu_{i}$ represents the expected growth rate of the value of assets for firm $i, \sigma_{i}$ is the volatility of asset value, $W_{i, t}$ is a Wiener process, and $n$ is the number of firms. We assume $\mu_{i}$ and $\sigma_{i}$ are constant. Applying Ito's lemma to the logarithmic transformation, we have:

$$
d \ln V_{i, t}=\left(\mu_{i}-\frac{\sigma_{i}^{2}}{2}\right) d t+\sigma_{i} d W_{i, t}
$$

And hence, starting from $V_{i, 0}$, the value of firm's $i$ assets at each point in time is:

$$
\ln V_{i, t}=\ln V_{i, 0}+\left(\mu_{i}-\frac{\sigma_{i}^{2}}{2}\right) t+\sigma_{i}\left(W_{i, t}-W_{i, 0}\right)
$$

In Merton's model, each firm receives a single loan [see Vasicek (2002)] and the firm defaults at maturity $T$ if the value of its assets $V_{i}$ falls below the contractual value of its debts $D_{i}$. The Modified Distance to Default of firm $i$ [following Hull et al. (2010)] at any point in time $t$ is defined as the logarithm of the leverage ratio, i.e., the value of firm $i$ assets divided by the contractual value of its debts, $V_{i, t} / D_{i, t}$, scaled by volatility, $\sigma_{i}$ :

$$
M D D_{i, t}=\frac{\ln V_{i, t}-\ln D_{i, t}}{\sigma_{i}}
$$

Using (3.3) and applying Ito's lemma under the assumption that the contractual value of debts $D_{i, t}$ is constant over time, we can see that $d M D D_{i, t}$ has a drift: $\gamma_{i}=\frac{\mu_{i}-\sigma_{i}^{2} / 2}{\sigma_{i}}$ and a unit variance: ${ }^{13}$

$$
d M D D_{i, t}=\gamma_{i} d t+d W_{i, t}
$$

Following Leland (2004), Hull et al. (2010) and Tarashev and Zhu (2008) the probability that the market value of assets of a given firm $i$ may fall below the value of its debt at any time in the next $\tau$ years is given by:

$$
P D_{i, t}\left(\tau, M D D_{i, t}, \gamma_{i}\right)=1-\Phi\left(\frac{M D D_{i, t}+\tau \gamma_{i}}{\sqrt{\tau}}\right)+\exp \left(-2 M D D_{i, t} \gamma_{i}\right) \Phi\left(\frac{-M D D_{i, t}+\tau \gamma_{i}}{\sqrt{\tau}}\right)
$$

\footnotetext{
${ }^{13}$ Jump diffusion elements have been introduced in some models to avoid the fact that under an Arithmetic Browninan motion, MDD will diverge over time to zero with probability 1, which may be reasonable in a growing economy, but not so much in downturns.
} 
On the other hand, under market clearing, the present value of CDS premium payments (left-hand side of the equation) must be equal the present value of protection payments (the right-hand side):

$$
s_{i, t} \int_{t}^{t+T} e^{-r_{\tau} \tau} \Gamma_{i, \tau} d \tau=L G D_{i, t} \int_{t}^{t+T} e^{-r_{\tau} \tau} q_{i, \tau} d \tau
$$

where $r_{\tau}$ stands for the risk-free rate of return, $s_{i, t}$ is the CDS spread on firm $i$ at time $t, L G D_{i, \tau}$ is the date- $t$ expectation of loss given default, and $q_{i, \tau}$ denotes the (annualized) unconditional risk-neutral default intensity, so that $P D_{i, \tau} \equiv \int q_{i, v} d v$ and $\Gamma_{i, \tau} \equiv 1-\int_{0}^{\tau} q_{i, v} d v$ is the associated risk-neutral survival probability over the following $\tau$ years. Under the standard simplifying assumptions that $r_{\tau}$ and $q_{i, \tau}$ are expected to be constant over time and LGD is independent of the variable(s) triggering default event, the previous equation implies that the one-year risk-neutral PD equals:

$$
P D_{i, t}=q_{i, t}=\frac{a_{t} s_{i, t}}{a_{t} L G D_{i, t}+b_{i} s_{i, t}}
$$

where $a_{t} \equiv \int_{t}^{t+T} e^{-r \tau} d \tau$ and $b_{t} \equiv \int_{t}^{t+T} \tau e^{-r \tau} d \tau .{ }^{14}$

The right hand side of equations (3.6) and (3.8) should give us the same PD estimate, which allows us to solve for MDD for a one-year horizon $(\tau=1) .^{15}$

Our assumption that the volatility, the drift and the contractual value of debts are constant could be relaxed following the analysis in Du et al. (2016). That would be a relevant extension of our model that would allow for the analysis of interesting issues regarding the risk of default that cannot be discussed in our simplified framework.

\subsection{Correlation models with a single systemic factor}

To obtain sensible value-at-risk estimates from the simulation exercise it is crucial to maintain the appropriate correlations among the change over time in the value of assets of the different firms. We initially follow Dullmann et al. (2007) to consider one-factor correlation models. In a later section we will extend his analysis to compare with alternative model specifications with two sources of systemic risk.

\footnotetext{
${ }^{14}$ When running simulations below we will use the closed form expressions for these two integrals, $\int_{t}^{t+T} e^{-r \tau} d \tau=\frac{1}{r} e^{-r t}(1-$ $\left.e^{-r T}\right)$ and $\int_{t}^{t+T} \tau e^{-r \tau} d \tau=\frac{1}{r} e^{-r t}\left[\left(\frac{1}{r}+t\right)-\left(\frac{1}{r}+t+T\right) e^{-r T}\right]$

${ }^{15}$ Once we have MDD data for each firm and time period, we could also estimate the correlation $\rho_{i, j}$ between the value of assets of any two firms by: $\rho_{i, j}=\operatorname{corr}\left(\Delta \ln V_{i, t}, \Delta \ln V_{j, t}\right)=\operatorname{corr}\left(\Delta M D D_{i, 0}, \Delta M D D_{j, 0}\right)$, which would allow us to analyze interesting risk management issues, but we do not pursue that line of analysis here.
} 
In models with one systemic risk factor, standardized percent changes in the value of assets of firm $i, v_{i, t}=\frac{\ln V_{i, t}-\ln V_{i, t-1}}{\sigma_{i}}$, are represented as the aggregate of two uncorrelated Normal $(0,1)$ components, one being a risk factor $X$ common to other firms, and a second one being a firm-specific, idiosyncratic shock, $\xi_{i}$ :

$$
v_{i, t}=r_{i} X+\sqrt{1-r_{i}^{2}} \xi_{i}
$$

As a consequence, the return on the firm's $i$ assets will also follow a Normal $(0,1)$ distribution. In this model, the systemic risk factor $X$ may be global, being common to all firms in the sample, or sectorspecific. In turn, the $r_{i}$ parameters can be firm-specific or sector-specific, depending on the model, which it will give rise to four different correlation models. Correlations across firms then emerge from the common risk factor. From (3.3) and (3.5) we have: $v_{i, t}=\frac{\ln V_{i, t}-\ln V_{i, t-1}}{\sigma_{i}}=\gamma_{i} \frac{1}{\sigma_{i}}+\left(W_{i, t}-W_{i, t-1}\right)=$ $\gamma_{i}\left(\frac{1}{\sigma_{i}}-1\right)+\triangle M D D_{i, t}$, so that we can use the weekly changes in the modified distance to default $\triangle M D D_{i, t}$ as a proxy for $v_{i, t}$ in equation (3.9) to estimate the correlation parameters $r_{i}$.

\subsubsection{Basel II IRB model (global systemic risk factor)}

The simplest one-factor correlation model considers a decomposition of changes in the value of assets of each firm, $v_{i, 1}$ into a common systemic global factor, $X$, representing an unobserved state (it could be the state of the economy or the level of stress in credit markets) and a firm specific factor, $\xi_{i}$ :

$$
v_{i, 1}=r_{i} X+\sqrt{1-r_{i}^{2}} \xi_{i}
$$

where $X, \xi_{1}, \xi_{2} \ldots \ldots, \xi_{n}$ are mutually independent standard Normal variables, with $n$ being the total number of issuers in our sample. The $\sqrt{1-r_{i}^{2}} \xi_{i}$ term represents the company specific or idiosyncratic risk. Our first model follows Basel II in choosing the value of $r_{i}^{2}$ as a function of the probability of default of firm $i$ as:

$$
r_{i}^{2}\left(P D_{i}\right)=0.24-0.12 \cdot\left(1-\exp ^{-50 \cdot P D_{i}}\right)
$$

and we take the positive square root of $r_{i}^{2}\left(P D_{i}\right)$ to simulate trajectories for the value of assets of each firm. This function was proposed by Lopez (2004) by calibration of the one-factor KMV model to replicate empirically observed correlations. ${ }^{16}$

\footnotetext{
${ }^{16}$ For a critical discussion of this model, see Gianfrancesco et al. (2011).
} 


\subsubsection{Market model (global systemic risk factor)}

The market model considers again a common global risk factor $X$ for all issuers, as in (3.10). The difference with the Basel II IRB model is that the correlation parameter $r_{i}$ is now defined endogenously. Since the model implies a linear correlation:

$$
\operatorname{Corr}\left(v_{i, 1}, X\right)=\operatorname{Cov}\left(v_{i, 1}, X\right)=\operatorname{Cov}\left(r_{i} X+\sqrt{1-r_{i}^{2}} \xi_{i}, X\right)=r_{i} \operatorname{Var}(X)=r_{i} \quad i=1,2, \ldots, n
$$

we can estimate $r_{i}$ for each firm as the correlation between weekly changes in $\Delta M D D_{i, t}$ as a proxy for the value of firms' assets $v_{i, 1}$ and the chosen common risk factor $X .{ }^{17}$

The correlation between the value of assets for any two firms, $i, j$ will be: $\operatorname{Corr}\left(v_{i, 1}, v_{j, 1}\right)=\operatorname{Cov}\left(r_{i} X+\right.$ $\left.\sqrt{1-r_{i}^{2}} \xi_{i}, r_{j} X+\sqrt{1-r_{j}^{2}} \xi_{j}\right)=r_{i} r_{j}$, with independence of whether they belong or not to the same sector.

\subsubsection{Sectorial Market model (global systemic risk factor)}

As in the Market model above, the Sectorial Market model assumes that all firms in a given sector share the same risk factor, but it restricts the correlation parameter to be the same for all firms in a given sector.

$$
v_{i, 1}=r_{s} X+\sqrt{1-r_{s}^{2}} \xi_{i}
$$

Correlations with the risk factor are:

$$
\operatorname{Corr}\left(v_{i, 1}, X\right)=\operatorname{Cov}\left(v_{i, 1}, X\right)=\operatorname{Cov}\left(r_{s} X+\sqrt{1-r_{s}^{2}} \xi_{i}, X\right)=r_{s} \operatorname{Var}(X)=r_{s}
$$

an equality that holds for each single firm in sector $s$. Hence, a sensible robust estimate of the $r_{s}$ parameter to avoid the influence of potential outliers would be the median of intra-sector correlations between changes in the value of each firm and the sectorial index:

\footnotetext{
${ }^{17}$ This is similar in spirit to the Generalized Method of Moments estimator in that we choose parameter values so that the model implied correlations between changes in the value of assets of individual borrowers and the systemic factor be equal to the analogue sample moments.
} 


$$
r_{s}=\operatorname{med}_{i \in s}\left[\operatorname{Corr}\left(v_{i, 1}, X\right)\right]
$$

The correlation between the time evolution of the value of assets for two firms, $i, j$ in sectors $s, z$ will be: $\operatorname{Corr}\left(v_{i, 1}, v_{j, 1}\right)=\operatorname{Cov}\left(r_{s} X+\sqrt{1-r_{s}^{2}} \xi_{i}, r_{z} X+\sqrt{1-r_{z}^{2}} \xi_{j}\right)=r_{s} r_{z}$, while firms $i$ and $j$ in the same sector $s$ will have a correlation: $\operatorname{Corr}\left(v_{i, 1}, v_{j, 1}\right)=\operatorname{Cov}\left(r_{s} X+\sqrt{1-r_{s}^{2}} \xi_{i}, r_{s} X+\sqrt{1-r_{s}^{2}} \xi_{j}\right)=r_{s}^{2}$

\subsubsection{Sectorial model (sectorial systemic risk factor)}

In the Sectorial model we consider a different risk factor for each sector. For a firm $i$ in sector $s$, this model assumes that changes in the value of assets are driven by the sectorial systemic factor $X_{s}$ according to:

$$
v_{i, 1}=r_{s} X_{s}+\sqrt{1-r_{s}^{2}} \xi_{i}
$$

Therefore, $r_{s}$ measures firm $i$ 's sensitivity to its own sector systemic risk. The $\xi_{i}$ terms represent again idiosyncratic shocks, independent across firms. Since the correlations with the sectorial index are:

$$
\operatorname{Corr}\left(v_{i, 1}, X_{s}\right)=\operatorname{Cov}\left(v_{i, 1}, X_{s}\right)=\operatorname{Cov}\left(r_{s} X_{s}+\sqrt{1-r_{s}^{2}} \xi_{i}, X_{s}\right)=r_{s}
$$

then, the $r_{s}$ parameter can be estimated by:

$$
r_{s}=\operatorname{med}_{i \in s}\left[\operatorname{Corr}\left(v_{i, 1}, X_{s}\right)\right]
$$

The sectorial factor returns $\left\{X_{s}\right\}_{s=1,2 \ldots \ldots . N}$ will have a correlation matrix:

$$
\operatorname{Var}\left(X_{1}, X_{2}, X_{3}, \ldots ., X_{N}\right)=\left[\begin{array}{ccccc}
1 & \omega_{12} & \omega_{13} & \ldots \ldots & \omega_{1 N} \\
\omega_{21} & 1 & \omega_{23} & \ldots \ldots & \omega_{2 N} \\
\omega_{31} & \omega_{32} & 1 & \ldots \ldots & \omega_{3 N} \\
\ldots \ldots & \ldots & \ldots & 1 & \ldots \\
\omega_{N 1} & \omega_{N 2} & \omega_{N 3} & \ldots . & 1
\end{array}\right]
$$


so that inter-sector correlations $\omega_{s z}$ could be estimated by the sample correlation between the sectorial factor returns for the $s$ and $z$ sectors: $\omega_{s z}=\operatorname{Corr}\left(X_{s}, X_{z}\right), s, z=1,2, \ldots, N$. The correlation between changes in the value of assets for two firms, $i, j$ in sectors $s, z$ will be: $\operatorname{Corr}\left(v_{i, 1}, v_{j, 1}\right)=$ $\operatorname{Cov}\left(v_{i, 1}, v_{j, 1}\right)=r_{s} r_{z} \omega_{s z}$, while for firms $i$ and $j$ in the same sector $s$, we will have: $\operatorname{Corr}\left(v_{i, 1}, v_{j, 1}\right)=$ $r_{s} r_{s} \omega_{s s}=r_{s}^{2}$.

\subsubsection{Individual Sectorial model (sectorial systemic risk factor)}

In the Individual Sectorial model, borrower $i$ 's standardised asset return is driven by the sector systemic factor $X_{s}$ according to:

$$
v_{i, 1}=r_{i} X_{s}+\sqrt{1-r_{i}^{2}} \xi_{i}
$$

The correlation parameter $r_{i}$ is now firm-specific. Since the correlation with the sectorial factor is:

$$
\operatorname{Corr}\left(v_{i, 1}, X_{s}\right)=\operatorname{Cov}\left(v_{i, 1}, X_{s}\right)=\operatorname{Cov}\left(r_{i} X_{s}+\sqrt{1-r_{i}^{2}} \xi_{i}, X_{s}\right)=r_{i}
$$

we can now estimate a different correlation parameter $r_{i}$ for each issuer $i$ in sector $s .{ }^{18}$

$$
r_{i}=\operatorname{Corr}\left(v_{i, 1}, X_{s}\right), i=1,2, \ldots, n ; s=1,2, \ldots, N
$$

Where $N$ denotes the number of sectors. The correlation between the change in the value of assets for firms $i$ and $j$ in the same sector $s$ is: $\operatorname{Corr}\left(v_{i, 1}, v_{j, 1}\right)=r_{i} r_{j} \omega_{s s}=r_{i} r_{j}$, while for two firms $i, j$ in different sectors $s, z$, we will have: $\operatorname{Corr}\left(v_{i, 1}, v_{j, 1}\right)=r_{i} r_{j} \omega_{s z}$.

\section{(INSERT HERE TABLE 4)}

\subsection{Time evolution of correlations}

In this section we analyze the time evolution of the estimated asset correlations. To reduce the amount of noise in CDS spreads, we work with weekly averages of daily data, and we use rolling window samples of 52 weeks to estimate the correlations between weekly changes in the value of assets for a given firm and the risk factor. We repeat this process 313 times, since we have 365 weekly data

\footnotetext{
${ }^{18}$ Notice that we estimate a single parameter for each firm using the time series for the value of assets of that firm, so that there is no problem with the number of degrees of freedom.
} 
points for each variable. ${ }^{19}$ According to each model, we use either a global or a sectorial risk factor, and the $r_{i}$ parameters are estimated as explained in the previous sections.

Regarding the choice of risk factors for the correlation models, one possibility would be to draw on business cycle variables, volatility indices, or illiquidity indicators, among others. We preferred to rely on using a Global Credit Risk Factor (GRF) in the models that incorporate a global risk factor, and a Sectorial Credit Risk Factor (SCRF) in the models that incorporate a sectorial risk factor. We estimate the GRF as the first principal component of weekly changes in CDS spreads for all the 881 firms in the sample. The SCRF factors were estimated as the first principal component of weekly changes in CDS spreads for the firms in each sector. This choice of global risk factors was successfully used in Chamizo and Novales (2016a) to decompose credit risk for individual firms into systemic and idiosyncratic components.

Figure 10.2 shows the time evolution of the median correlation of firms in each sector over the 2006-2012 period. Intra-sector correlations were low before mid-2007, when they increased sharply in all sectors. They decreased between September 2008 and the beginning of 2010, increasing somewhat at that point. After a new reduction they approached the pre-crisis levels, only to rise again in mid-2011 because of the downgrade of US debt. But it is clear that intra-sector credit correlations in stressed times are high, reflecting the greater importance of common sectorial and global risk factors (we provide a detailed description of each phase in section 4 below). The highest median intra-sector correlations arise in the government and the energy sectors, possibly because of the perception of potential contagion inside each monetary area. Intra-sector asset correlations are lower in healthcare and technology sectors, among others.

(INSERT HERE FIGURES 10.2, 10.3 AND 10.4)

Figure 10.3 displays median correlations between each sector and the financial sector, which have been consistently high over the sample, and more so in stressed periods. They increased at the onset of the crisis, in the summer of 2007, and also at the time of the European sovereign debt crisis, and they remained high, in the neighborhood of 0.90 , at the end of 2012. The financial sector displays a high correlation with the industrial sector, possibly because the latter includes real estate, to which financial institutions had large exposures. ${ }^{20}$ Healthcare and technology are the sectors having the lowest correlation with the financial sector. Correlations with the utilities sector in Figure 10.4 differ noticebly among sectors, but they swiftly increased in mid-2007. In mid-2011 they were back to the pre-crisis levels, only to rise again sharply in line with the behavior shown by intrasector correlations. Similar results, obtained under a different methodological approach, have been used by Chamizo and Novales (2016b) to suggest sectorial asset allocation recommendations.

\footnotetext{
${ }^{19}$ With 365 data points in the sample, we are forced to use rolling windows, even at the cost of introducing autocorrelation in the estimated parameters.

${ }^{20}$ The CAMEL (Capital adequacy, Asset quality, Management, Earnings, and Liquidity) regulatory bank ratings includes commercial real estate as a proportion of total assets as a measure of asset quality.
} 
Table 5 shows descriptive sectorial statistics for the correlations between the time series of estimated MDD and the global credit risk factor or the sectorial credit risk factor, respectively. As expected, correlations with the SCRF are generally higher than those with the GRF. Median correlations are higher than average correlations, showing that the distribution of the linear correlation coefficients is skewed to the left.

Figure 10.5 shows the empirical density of correlation coefficients between the MDD for each firm and the global risk factor at the beginning and the end of the sample $(2007,2012)$. Initially, $6 \%$ of the firms had zero-asset correlation with the systemic risk factor. At the end of the sample, that proportion was reduced to almost zero. We can see an evident shift to the right in the distribution of correlations, which were generally higher after the financial crisis than before the crisis.

\section{Credit VaR estimates}

In this section we report value-at-risk estimates for a global credit portfolio, made up by investing a 1/881 fraction of the initial money amount in each of the 881 issuers in our sample. Value-at-risk estimates are obtained by simulation of the proposed correlation models.

We start by simulating one million trajectories for the standardized global factors and sectorial factors, as well as for the idiosyncratic components of all firms in the sample, assuming a standard normal distribution for each one of them. Values for the sectorial factors are generated taking into account the correlations among them using the appropriate Cholesky factor, while idiosyncratic components are uncorrelated. Then, using the estimated correlation parameters, we can easily generate time paths for $v_{i, 1}$.

By definition, firm $i$ defaults the first time period when $\triangle M D D_{i, t}<N^{-1}\left(P D_{i, t-1}\right)$. But we have already seen that, under our maintained assumptions: $\triangle M D D_{i, t}=\gamma_{i}+\left(W_{i, t}-W_{i, t-1}\right)=\frac{\ln V_{i, t}-\ln V_{i, t-1}}{\sigma_{i}}=$ $v_{i, t}$, so that we will have default whenever $v_{i, t}<N^{-1}\left(P D_{i, t-1}\right)$. Once we have estimates for the correlation parameters, we can use each model to simulate trajectories for $v_{i, t}$. We start from the initial period distance to default, provided by (3.8) as a function of $P D_{i, 0}$, and we check whether the default condition holds at any time period. In that comparison we use the PD associated to the Moody's rating of each firm in the portfolio each period.

Along each simulated trajectory, the percentage portfolio loss is determined by $\operatorname{Loss}(\%)=\sum_{i=1}^{881} L G D_{i}$. $1_{v_{i, 1} \leq N^{-1}\left(P D_{i}\right)} / 881$, where the loss-given-default is $L G D_{i}=1-$ Recovery $y_{i}$, and data for Recover $y_{i}$ is taken from the Markit database for each issuer. That way, we have 1,000,000 numerical P\&L estimates for each firm that are aggregated into portfolio losses for each time period. Then, we take the 99.9th percentile, $q$, of the distribution of portfolio losses to determine the $V a R$ of the portfolio under each model.

Finally, we take as a benchmark the $V a R$ defined in the Basel II IRB model for corporate exposures 
as:

$$
\begin{gathered}
\operatorname{VaR}_{99.9 \%}^{\text {BaselII-IRB }}=\frac{1}{881} \sum_{i=1}^{881} L G D_{i} \cdot N\left(\frac{N^{-1}\left(P D_{i}\right)+\sqrt{r_{P D_{i}}^{2}} N^{-1}(1-q)}{\sqrt{1-r_{P D_{i}}^{2}}}\right) \\
r_{P D_{i}}^{2}=0.24-0.12 \cdot\left(1-\exp ^{-50 \cdot P D_{i}}\right)
\end{gathered}
$$

Figure 10.6 shows VaR estimates from the different one-factor correlation models (Market, Sectorial Market, Sectorial and Individual Sectorial). The four correlation models considered generate a similar pattern. This is to be expected, since they use the same market information, but several points are worth to be mentioning:

1. Models that consider individual correlation parameters lead to similar VaR estimates over the sample period. The time series for VaR estimates from the Market model and the Individual Sectorial model remain close at any time, with a median difference of 42 basis points (b.p.). This suggests that, as suspected, inter-sector correlations may have been very high during the 20072012 period. The BIS II model generated a clearly insufficient level of regulatory capital from the summer of 2007 onwards.

2. On the contrary, the Sectorial Market model yields a higher VaR estimate than the Market model over the June 2007-December 2012 period, with a median difference between VaR estimates above 200 b.p., a result in line with Dullmann et al. (2007). Thus, if we use the median correlation for an issuer instead of his "true" individual correlation, the change in VaR estimation can be considerable. This result suggests that some issuers with a large contribution to market VaR had a correlation with the common factor below the sector median correlation. Therefore, when we replace the issuer specific correlation by the median sector correlation, VaR estimates increase. That was not the case before the first occurrence of the crisis (June 2006-May 2007). The comparison between the Sectorial VaR and the Individual Sectorial VaR is similar, for the same reasons.

3. Finally, the difference between VaR estimates from the Market model and the Sectorial model combines two effects. On the one hand, the use of different common factors for the sectors in the Sectorial model allows for a higher diversification and hence, a lower VaR than in the Market one-factor model. On the other hand, the use of the median intra-sector correlation instead of the individual intra-sector correlation tends to increase VaR for the June 2007-December 2012 period, as explained above. Together with the previous remarks, the comparison between these two models shows that when specifying correlation models, the use of firm-specific versus sector-specific correlation parameters makes more difference for VaR estimation than the choice between using a global factor versus a set of sectorial factors. Whether these choices have an effect on the accuracy of VaR estimates should be analyzed by backtesting procedures, although a 
significantly longer sample would be required to get any conclusive evidence.

4. With 1,000,000 simulations, the confidence interval bands at reasonable significance levels [see Kendall and Stuart (1977)] are very narrow, implying that the fluctuations observed in VaR estimates or the differences in estimated VaR from different models are not just due to sampling error.

5. The residuals from regressions of weekly changes of our estimated VaR on weekly changes of our correlation estimates and the PD data from Moody's turned out to be very similar to those of the regression that uses correlation estimates as the only explanatory variable. Such an observation suggests the increased correlation in the credit market as the main cause of the increase in VaR during the financial crisis, with the increase in the physical probability of default playing a secondary role. This might have happened because rating firms did not update their downgrade data fast enough or because their over-the-cycle ratings are, by nature, not too sensitive to what are considered to be short-term events in the market.

\subsection{A narrative of the financial crisis as reflected in our credit VaR estimates}

There is a clear association between the different periods that can be observed in our VaR estimates and the economic events that occurred during the 2006-2012 period. We can distinguish several phases of this most serious crisis since the Great Depression (the index number for each phase is also shown on the graph): ${ }^{21}$

\section{(INSERT HERE FIGURE 10.6 )}

1. Subprime crisis: 2 April 2007: New Century Financial, largest U.S. subprime lender, filed for Chapter 11 bankruptcy, announcing the departure of more than half the workforce. July 2007: Bear Stearns' BSC.N \$850 million Asset-Backed Securities Fund experienced sharp declines in July, prompting some investors to seek redemption of their investments. 9 August 2007: BNP Paribas announced that it was ceasing activity in three hedge funds that specialized in US mortgage debt. It then became clear that there were tens of trillions of dollars worth of dodgy derivatives swilling round which were worth a lot less than the bankers had previously imagined. Nobody knew how big the losses were, and banks stopped doing business with each other. During this first phase, our estimate of Market VaR increased from 6.02\% in March 2007 to $12.25 \%$ at the beginning of August 2007, reflecting the current conditions of the economy at that time.

2. Lehman default: 17 February 2008: Northern Rock was nationalized in what was announced as a temporary measure, although it would be nearly four years before it returned to the private sector. 16 March 2008: Bear Stearns was acquired for $\$ 2$ a share by JP Morgan Chase in a fire sale avoiding bankruptcy. The deal was backed by the Federal Reserve, providing up to $\$ 30 \mathrm{bn}$ to cover possible Bear Stearns losses. 19 June 2008: Managers of the Bear Stearns CDO hedge

\footnotetext{
${ }^{21}$ Sources: Federal Reserve Bank of St. Luis, The Federal Reserve Bank of Minneapolis, Bloomberg and The Guardian.
} 
funds that crashed in 2007 were arrested by the Federal Bureau of Investigation accused of misrepresenting their funds' true condition to investors, although they were acquitted. 7 September 2008: The US government bailed out Fannie Mae and Freddie Mac. 15 September 2008: the US government allowed the Lehman Brothers investment bank to go bankrupt. Up to that point, it had been assumed that governments would always step in to bail out any bank that got into serious trouble, as with Bear Stearns in the US and Northern Rock in the UK. During this period Market VaR increased from $12.24 \%$ on 22 February 2008 to $14.57 \%$ on 10 October 2008, reaching one of the highest historical VaR levels.

3. US Stimulus Act: The American Recovery and Reinvestment Act of 2009 (ARRA) (Pub.L. 111-5), commonly referred to as the Stimulus or Recovery Act, was an economic stimulus package enacted by the 111th United States Congress in February 2009 and signed into law on 17 February 2009 by President Barak Obama. 2 April 2009: At the London G20, world leaders committed themselves to a $\$ 5 \mathrm{tn}$ (£3tn) fiscal expansion, an extra $\$ 1.1 \mathrm{tn}$ in resources to help the International Monetary Fund and other global institutions boost jobs and growth, and to reform the banks. During this period of government stimulus measures, we observe that the Market VaR decreased from $13.14 \%$ on 23 January 2009 to $9.41 \%$ on 8 January 2010. It is worthwhile to notice the downward stickiness in VaR, which it did not decreased proportionally as much as it had increased during the previous two events.

4. Eurozone crisis: 27 April 2010: Greek debt was downgraded to junk on May 2, 2010. In a move that signaled the start of the eurozone crisis, Greece was bailed out for the first time, after eurozone finance ministers agreed loans worth $€ 110 \mathrm{bn}$. This intensified the austerity program in the country, sending hundreds of thousands of protesters to the streets. 28 November 2010: European ministers agreed a bailout for Ireland worth €85bn. This marked the point at which the focus of concern switched from the private to the public sector. Market VaR started this period at $10.31 \%$ on 29 January 2010, ending it at $13.39 \%$ on 31 December 2010.

5. EU measures: 11 March 2011: The EU summit agreed to expand powers of the European Financial Stability Facility (EFSF) to allow it to buy debt in primary markets and tap its full €440bn in firepower. The EU also reached preliminary agreement to cut the rates on emergency loans to Greece by 100 basis points for the first three years and extend maturities of the loans to 7.5 years. 21 March 2011: EU finance ministers decided on mechanisms for allowing the region's permanent bailout mechanism, the ESM, to lend €500bn from 2013. 5 May 2011: The ECB bailed out Portugal. 13 June 2011: S\&P cut Greece to CCC, the lowest rating for any country that S\&P reviews in the world. During this period, troubles in Europe did not extend to the rest of the world, and the Market VaR decreased from 13.08\% on 14 January 2011 to $8.53 \%$ on 1 July 2011.

6. US rating downgrade: 5 August 2011: S\&P downgraded US sovereign debt, which had had an AAA credit rating from S\&P since 1941. The S\&P 500 Stock Index had fallen 10.8 percent in the previous ten trading days on concerns that the U.S. economy might have been heading into another recession and because the European debt crisis had worsened. 15 September 2011: ECB 
offered banks unlimited dollar loans for three months as the worsening debt crisis sparked concern over some institutions struggling to access U.S. currency. 17 September 2011: U.S. Treasury Secretary urged European officials to deal with the crisis and avoid "catastrophic risks" after flying to a meeting of European Union finance chiefs in Poland. 19 September 2011: Standard \& Poor's cut Italy's credit rating for the first time in almost five years, downgrading it to A from A+. 7 October 2011: Fitch cut Spain to AA- and Italy to A+. 12 March 2012: Unemployment in Europe reached its highest level ever. 12 June 2012: The level of Spanish borrowing reached a record high. The consequences of the US downgrade were very deep, with Market VaR increasing from 8.52\% on 5 August 2011 to $15.44 \%$ on 22 June 2012, the highest Market VaR during the 20062012 period. Credit VaR and regulatory capital based on backward looking correlation estimates were depressed in this period, while many international and large regional banks were reporting elevated default rates well into 2012.

7. Draghi measures: 26 July 2012: ECB president Mario Draghi unexpectedly gave his strongest defense yet of the euro, prompting markets to rally. Thus, Market VaR went down from $15.44 \%$ to $11.78 \%$ at the end of 2012 .

These events led to an increased asset correlation, as well as to higher volatility, in estimates of required capital. For instance, the increase in average CDS spreads by $23 \%$ during the third week of July 2007 brought up an increase in average correlation (based on MDD changes) from 0.25 to 0.38 . In the following week, the downturn in the credit market was also quite pronounced, with another average increase of $13 \%$ in CDS spreads. ${ }^{22}$

\subsection{Robustness analysis}

In this section we report the results of several analyses of sensitivity of our value-at-risk estimates to different modelling choices. They have to do with the value of the drift in the stochastic process for the value of firms' assets, the exclusion from our sample of the more idiosyncratic sectors, and the use of statistical filters to smooth out the excess noise in CDS data.

$\underline{\text { Numerical value of the drift parameter: We tried different values of the drift } \gamma \text { in the }[0,0.1] \text { interval }}$ to solve equation (3.6), but the estimates of the asset correlations $\rho_{i, j}$ are virtually insensitive to the chosen value of $\gamma$, as advanced by Tarashev and Zhu (2008). Using $\gamma=0$ versus $\gamma=0.1$ in the Market model leads to a difference in the 275.753 correlation estimates [881 issuers, times 313 weekly observations], $r_{i}^{2}=\left[\operatorname{Corr}\left(\Delta M D D_{i}, \Delta X\right)\right]^{2}$, between 11.32 and 10.22 basis points. Hence, we just report below estimation results for $\gamma=0$.

\footnotetext{
${ }^{22}$ These market movements were just the reflection of the volatility in correlation estimates for particular issuers. For instance, the spread in the 5-year CDS contract for GAP (one of the largest American multinational clothing and accessory retailers) went up from 125 to 150 basis points (b.p.) during the third week of July 2007, reaching 175 basis points the following week. Incorporating these two weekly outlier returns caused the correlation estimate for GAP to increase considerably, contributing to a sharp increase in correlation in the credit market and hence, significantly raising capital requirements.
} 
Exclusion of idiosyncratic sectors: We estimated again the credit value at risk of our global portfolio excluding the Government and Financial sectors, since they have a different nature than the rest of corporate sectors. A similar exclusion has been done by Elkamhi et al. (2012), among others. Figure 10.7 shows that the broad time pattern of value-at-risk estimates excluding these two sectors is the same as in the estimates obtained with the whole sample of sectors. The level of value at risk is now somewhat higher because the excluded sectors contain a large percentage of issuers of IG quality. This is also reflected in capital requirements from the BIS model, which are now also a bit higher.

\section{(INSERT HERE FIGURE 10.7 )}

Filtering the data: Finally, we applied the Hodrick-Prescott filter to the weekly CDS data to eliminate possible high frequency noise that could contaminate our estimates, with a negligible effect on value-at-risk estimates. A similar conclusion is reached if the filter is applied to the time series of correlation estimates before we use them to estimate value at risk by repeated simulation of the Merton model.

\section{Expected Shortfall analysis}

Value at risk $(\mathrm{VaR})$ is a simple risk indicator that measures what loss will be exceeded only a small percentage of times in the next $k$ trading days. As a measure of risk, VaR has some limitations: VaR at the level $\alpha$ gives no information about the severity of tail losses. Furthermore, VaR may fail to be subadditive, depending on the fatness of the tails of the probability distribution of returns, as discussed by Daníelsson et al. (2013). The lack of subadditivity contradicts the notion that there should be a diversification benefit associated with merging portfolios. As a consequence, a decentralization of risk management using VaR is difficult since we cannot be sure that by aggregating VaR numbers for different portfolios or business units we will obtain a bound for the overall risk of the enterprise. Failure to be subadditive would also preclude VaR from being a coherent measure of risk.

The drawbacks of VaR as a risk measure are behind the 2010 shift of the Basel Committee in Banking Supervision to Expected Shortfall (ES) as a more appropriate risk measure. ES accounts for the magnitudes of large losses as well as the probabilities that they occur. More specifically, ES gives us the expected value of the loss $k$ days ahead, conditional on it being worse than the VaR at a given level $\alpha$. Thus, a precise estimate of VaR is still a requirement when using ES as the risk measure of reference. Even though ES is clearly a better indicator of a risk position, its use has some difficulties, as pointed out by Kinateder (2016). ${ }^{23}$ One of them refers to the difficulty of backtesting ES, as opposed to the ease of VaR backtesting (see Novales and Garcia-Jorcano (2018) for a comparison of alternative approaches to ES backtesting).

\footnotetext{
${ }^{23}$ Kinateder (2106) compares the minimum capital requirements that arise under Basel II, the 2010 version of Basel III, and the 2013 version of Basel III.
} 
To complement our analysis of VaR estimates under the different correlation models, Figure 10.10 shows ES estimates from the four correlation models. As expected, the ES estimates follow the time pattern of VaR estimates, with a median difference through the sample of 400 basis points. We do not have a reference estimate of ES obtained from the Basel model, but the underestimation of VaR we have shown in previous sections suggests a similar underestimation of ES.

(INSERT HERE FIGURE 10.10 )

\section{Risk analysis with corporate bond data}

A natural question refers to whether the results shown in previous sections are specific to forwardlooking measures of risk. A reduced relevance of the CDS market is an additional reason to look at other markets. In this section we use corporate bond data to estimate value at risk and compare the results with those obtained with CDS data for the same set of firms. Given the complexity of bond data, we perform the analysis with a reduced sample of issuers. We take bond data for the June 2006June 2018 period from current issuers included in the MARKIT CDX.NA.IG.31 12/23 index. We started with an initial group of 125 firms, those for which we had historical prices in either BGN or CBBT, and 1043 bonds. All data are in USD. We considered senior unsecured bullet bonds to avoid the price of the bond being affected by the existence of a callable option, and we only included issues over 500 million USD to have some guarantee of liquidity. These two filters help us to interpret the bond spread as reflecting credit quality, although there will still be some basis risk remaining. We also took those bonds for which we have data at least $90 \%$ of the weeks over the sample period. After application of the filters we ended up with a portfolio of 45 Investment Grade issuers from the US. At any given point in time we take for each firm the bond closest to 5 -year maturity, since we want to compare VaR estimates with those obtained from 5-year CDS spreads. We did not include any bond with maturity below one year. With the filtered data we obtain the asset swap spread, calculating the weekly average of the available daily data over any given week. Finally, we adjusted the asset swap by the spread between the swap curve and the 5-year Treasury, so that the spread is referred to the risk-free curve. We estimated missing weekly spread data by taking the previous observation adjusted by the average spread change observed that week for the firms in the portfolio.

We report the results of value-at-risk estimation under the Market model. Computing sectoral factors with only 45 issuers in the sample does not seem too appropriate. We take as global risk factor for the bond and CDS portfolios the Bloomberg Barclays US Corporate Total Return Value Unhedged USD index. This index includes the investment grade, fixed rate, and taxable corporate bond market. It incorporates USD denominated securities publicly issued by US and non-US industrial, utility and financial issuers. To be consistent with CDS data, we have used the index calculated with option-adjusted spreads (OAS), the spread between a fixed-income security rate and the risk-free rate of return adjusted to take into account the embedded option. Typically, an analyst uses the Treasury securities yield 
for the risk-free rate. The spread is added to the price of the fixed-income security to make the prices of the risk-free bond and the corporate bond equal to each other. Following Lando (1998) and Duffie and Singleton (1999), we assume that such a spread in the corporate bond compensates only for credit risk, and it is therefore comparable with the spread in the credit default swap for that same firm. ${ }^{24}$

Figure 10.8 shows that median asset correlations follow a very similar pattern in bond and CDS data. They departed between August 2009 and August 2011, when the correlations in CDS data were much higher. This was a period of low liquidity in the corporate bond market [see Goldberg and Nozawa (2018)], which may have reduced the level of asset correlation. Gross positions among primary dealers increased throughout the period, closing the gap between corporate bond and CDS correlations. On the contrary, correlations in bond data have been higher since June 2014, although the correlations in both datasets exhibit similar fluctuations since March 2016. In this period inflation has followed an approximate linear trend from $0 \%$ to almost $3 \%$. Unfortunately, these explanations of the gaps of opposite signs between the level of asset correlation in the corporate bond and CDS markets are purely tentative and they would require further work to be confirmed.

Figure 10.9 shows that value-at-risk estimates obtained with CDS and bond data are quite similar. They differ at some specific points in time, which would be interesting to analyze further. Missing data are more frequent in bond data than in CDS data, and they are subject to a higher number of filters, which can explain some of the differences observed between the estimates obtained with both portfolios. The correlation and value-at-risk figures are similar because the correlation model that is simulated to estimate value at risk depends just on the correlation parameter and the default probability, which changes infrequently.

As with the large portfolio analyzed above, CDS data show an increase in risk in mid-2008 that is not reflected in bond data. After some improvement in market conditions, there is a sudden increase in risk again in the summer of 2011, because of the US rating downgrade and the crisis of sovereign debt in Europe. Value-at-risk estimates show a clear improvement in market conditions following Draghi speech in July 2012. Bond data again suggest an increase in risk in October 2014 that is not so evident in CDS data, followed by a further deterioration in March 2016. We have a preference for CDS data because of its forward-looking nature, but explaining the differences between the estimates obtained from both datasets since mid-2014 remains as an interesting question for further research.

Indeed, value-at-risk estimates with this smaller sample reflect the situation of the US economy over the years. As expected, the level of value at risk differs from that obtained with the portfolio of 881 firms. The current portfolio has a clear geographic concentration in the USA and most firms are

\footnotetext{
${ }^{24}$ As an alternative, we could have used the composite spread of firms with BBB rating for each sector as considered by Bloomberg, but that data starts in 2009. Still other possibility would be to use the CDX index, but we believe that the market risk factor would then be highly correlated with the portfolio, leading to a clear bias in the estimation of asset correlations. Something similar would happen if we used as market risk factor the first principal component of bond and CDS data, since the number of firms in the portfolio is small.
} 
IG, with an A rating. This explains that the required capital is now smaller than for the portfolio of 881 firms, which was global and contained assets of different credit quality.

In summary, with the natural differences due to the composition of the portfolio, the correlation estimation strategy we have followed seems to work well with both types of data, appropriately capturing the market situation at each point in time. Over 2015, and again since mid-2017, the value at risk of this high quality portfolio was close to the level estimated by the BIS II model. Nevertheless, over most of the sample the BIS II model underestimated risk, so that our model could be used to estimate an add-on of capital as a function of the economic cycle.

(INSERT HERE FIGURES 10.8 AND 10.9 )

\section{Model validation}

In this section we pursue two different strategies for model validation. We first examine the potential of our correlation estimates as predictors of economic events. As a proxy of changes in economic prospects, we take the number of downgrades and upgrades in Investment Grade ratings. After that, we perform a simulation analysis of a theoretical economy based on our correlation model to see the extent to which the estimates of the correlation parameter would coincide with the parameter value chosen for the simulation.

Karagozoglu and Jacobs (2016) modeled the relationship between risk signals in the credit default swap market and agency credit ratings, and characterized the factors that help explain the variation in such signals. We assume that changes in risk conditions in the credit market are well represented by rating changes and we examine whether our model anticipates decision by rating agencies. Indeed, quarterly aggregates of asset correlation estimates from bond and CDS data show a significant linear correlation with the number of downgrades in the same quarter as well as over a one-year period. In the case of CDS data the contemporaneous correlation and the correlation over the following 3 quarters is: $0.50,0.47,0.47,0.42$, whereas for the bond data estimates, those linear correlation coefficients are: $0.42,0.50,0.47,0.38$. After that, linear correlation is much weaker. A similar relationship is not observed with upgrades. A fourth-order vector auto-regression estimated with this quarterly data produces a significant response of downgrades to an unexpected increase in asset correlation that reaches its maximum between 3 and 4 quarters after the shock [see Figure 10.11] ${ }^{25}$ Hence, our correlation models can anticipate losses derived from risk concentration in credit portfolios.

\section{(INSERT HERE FIGURE 10.11)}

As a second validation test, we analyze the precision of estimates of the correlation parameter from the Sectorial Market model. In that model the correlation between the value of assets of any two firms

\footnotetext{
${ }^{25}$ We use quarterly data on upgrades and downgrades from Bloomberg, since 2008. Estimation results are not shown to save space. Lag length was determined by likelihood-based information criteria.
} 
in the same sector, normalizad to have a unit variance, is $r_{s}^{2}$. We start by simulating the model to generate time series of 365 weeks for the value of assets of 100 firms. The common factor and the idiosyncratic term are drawn independently of each other, with a standard normal distribution. ${ }^{26}$ The 4,950 pairwise linear correlations between any two firms are, on average, very close to the true parameter value, $r_{s}^{2}$. However, deviations from that mean are higher for low values of $r_{s}$ and, more importantly, the coefficient of variation increases even more rapidly for low values of $r_{s} .{ }^{27}$ In parallel with this observation, correlation estimates, being unbiased for any value of $r_{s}$, also show a higher standard deviation and higher coefficient of variation for low values of the asset correlation parameter. To give some insight into this property, let us mention that in a realization of the Monte Carlo simulation exercise, the coefficient of variation of the correlation estimate was $10 \%$ for $r_{s}=0.70,15 \%$ for $r_{s}=0.50$, and $30 \%$ for $r_{s}=0.30$. That means that while our estimation strategy seems to work well for portfolios with moderate to high asset correlation, it may lead to a significant estimation error for low asset correlations. With the linear correlations in Table 5, we seem to be on the safe side, expecting to have an estimation error of around $15 \%$ of the true value of the correlation parameter. Similar analysis could be done with other correlation models.

\section{Correlation models with two systemic risk factors}

A well-specified factor model must produce an error term (the idiosyncratic component of risk) that must be uncorrelated across firms. That may be hard to get with a one-factor model due to the existence of other common effects not captured by the single factor. Therefore, we also consider twofactor models:

$$
v_{i, 1}=r_{i} X+\beta_{i} Z+\sqrt{1-r_{i}^{2}-\beta_{i}^{2}} \xi_{i}
$$

where $Z$ represents a second risk factor that is uncorrelated with $X$, so that it does not bring any redundant information into the model. The $X$ and $Z$ factors can be global or sector-specific, and the $r_{i}$ and $\beta_{i}$ parameters may again be firm-specific or sector-specific, depending on the model. The term $\sqrt{1-r_{i}^{2}-\beta_{i}^{2}} \xi_{i}$ represents the idiosyncratic component of firm $i$. In practical applications, once we have selected the indicator variable $Z^{*}$ to be used as a second factor, we estimate a regression of $Z^{*}$ on $\mathrm{X}$ using a rolling window sample made up by 52 weekly observations and use the residuals from that regression as factor $Z$ in the previous equation. The properties of the OLS estimator guarantee the lack of correlation between both factors. Risk factors will again be standardized, so we will assume $X, Z, \xi_{i} \forall i$ to be pairwise independent standard Normal variables and, as a consequence, changes in

\footnotetext{
${ }^{26}$ A simulation exercise similar to the one performed in Strebulaev (2007)

${ }^{27}$ The coefficient of variation is the standard deviation as a percentage of the mean value
} 
the value of the firm, $v_{i}$, will also follow a $\operatorname{Normal}(0,1)$ distribution.

We initially consider VIX (Chicago Board Options Exchange Market Volatility Index) as the second systemic global factor. Being an average of implied volatilities obtained from option quotes, it would bring to the model an estimate of the market forward-looking perception of risk that would seem a natural risk factor for the credit market. In the Sectorial and Individual Sectorial models, the orthogonalization of VIX is obtained using the sectorial versions of the credit risk factor, so that the orthogonalized VIX component will be very similar across sectors but not identical, because the credit risk factor $\mathrm{X}$ is sector specific.

Table 6 displays the two-factor model specifications as well as the expressions for the correlation between any two firms in the same or in a different sector. The correlations with the two risk factors have not been included in the table, since they are similar to the ones in one-factor models, and they are estimated similarly. Using the same rolling window sample scheme as in one-factor models, we obtained a set of parameter estimates for each of the 313 weeks between January 2007 and the end of 2012.

Sectorial correlations with the orthogonalized VIX factor sharply increased between September 2008 and March 2010, the Government sector being the one with the highest correlation. Figure 10.12 shows the time evolution of VaR estimates obtained from models that use VIX as the second risk factor, together with the estimate of VaR obtained under the one-factor Basel formula. The general pattern is very similar to the one we obtained with the one-factor model, so that the evidence on the underestimation of risk by the Basel formula is robust to the addition of a second risk factor.

Figure 10.13 shows that the difference between VaR estimates from the analogue two- and onefactor models is not constant. One-factor models underestimate risk prior to September 2009. In that period, the two-factor VaR estimate is between $20 \mathrm{pb}$. and $40 \mathrm{pb}$. above the one-factor estimate, except for the trend observed during 2009, when the difference increased to almost 100 bp.. Such differences between both VaR estimates can be substantial for portfolios with a large nominal value. After September 2009, financial markets improved thanks to the reforms by President Obama and the G20 group. Both VaR estimates decreased, and especially so the two-factor model estimate, so they became more similar.

As an alternative, we use MSCI indices as the second risk factor. The stock market tends to move opposite to spreads in the credit market, since good news for a firm will raise their market value while decreasing the perception of risk on loans. Indeed, Chamizo and Novales (2016b) document large negative linear correlations between MSCI sectorial indices and the corresponding credit sectorial indices. At a difference of VIX, there are sectorial versions of MSCI that we will use as the second risk factor in the Sectorial and Individual Sectorial models, similarly to what we did with the credit risk factor X. Daily MSCI index data was extracted from Blomberg. Figures 10.14 show that VaR estimates from both two-factor specifications are very close to each other, in spite of the different nature of the 
second factor in both cases. That also means that the volatility VIX index and the MSCI indices were able to provide the same additional information to the one-factor model, especially during the crisis period (August 2008-November 2009).

\subsection{The dimensionality of factor correlation models}

Using the right number of factors is clearly the most important feature of the correlation models we have been using throughout the paper. ${ }^{28}$ The high explanatory power of our proposed global risk factor (GRF) makes it a good choice as a first factor, but we have also shown that a second factor adds relevant information on asset correlations in stressed times. However, the fact that alternative choices of a different nature for a second factor, like VIX and MSCI indices, lead to very similar correlation estimates and almost identical VaR estimates, suggests that there is not much additional information that could be used to estimate asset correlation.

To confirm that conjecture, we examine the amount of common information among the CDS issuers in our sample. To make the problem computationaly feasible, we take random samples of 100 firms from the 881 CDS issuers and compute the correlations between the weekly changes in their asset values, the $\nu_{i 1}$ variable in section $3 .{ }^{29}$ On the average, over a set of 50 random sample draws, the $90 \%$ interval for correlations between $\nu_{i 1}$ variables was $(0.16 ; 0.66)$. All of these correlations were positive, reflecting the syncronicity of asset values. When we consider the component of $\nu_{i 1}$ not explained by our estimated GRF, that interval was reduced to $(-0.18 ; 0.29)$, showing that the first risk factor explains a substantial amount of the common information among asset values. The use of a second factor, VIX or MSCI indices, implies a slight additional reduction in correlation, since the information of these factors is relevant just at specific points in the sample, as explained in previous sections.

Using a principal component methodology, we obtain that just 3 linear combinations of the $\nu_{i 1}$ variables is enough to explain $50 \%$ of the volatility in the asset value of the 881 firms throughout the sample. When considering the components of $\nu_{i 1}$ not explained by the GRF the number of required linear combinations increases to 12 , on average. A similar observation applies to higher volatility proportions, showing again the reduction in the amount of common information in firms' asset value from using our proposed factor models.

If we had to choose a third risk factor, it would be hard to beat the first principal component of the $\nu_{i 1}$ variables across the 881 firms, in terms of information content. We estimated regressions of $\nu_{i 1}$ on that principal component, obtaining that $90 \%$ of the R-squared values were below 0.66 . When

\footnotetext{
${ }^{28}$ The information criteria introduce in Bai and $\mathrm{Ng}$ (2002) have been extensively used to characterize the right number of factors (see also Bada et al. (2014) and Kinateder and Wagner (2017) for a discussion in a panel data framework). Unfortunately, our framework does not allow us to take advantage from those analysis. First, it is very important that the factors are observable, so that we can refer the model implied correlations to the state of the economy and the financial markets. Second, with 881 CDS issuers, the available upper bounds for the number of factors would be too large.

${ }^{29}$ With 100 firms we have 4,950 diferent pairwise correlations. Working with the 881 firms would yield 387,640 such correlations
} 
we performed a similar exercise for the components of $\nu_{i 1}$ not explained by the one-factor and twofactor models, $90 \%$ of the R-squared values were below 0.29 . Once again, this shows that our proposed factor models reduce drastically the amount of common information among the time series for the asset values of the firms in our sample. This does not show that there is not a chance of adding a third risk factor to our models, but it would seem rather hard to characterize an observable variable representing such a factor.

\section{Implications for regulator y credit risk modelling}

The literature on model risk [see for example FED (2011)] places special emphasis on the importance of the development, implementation and use of a given risk model. It also underscores the need to include backtesting and benchmarking risk estimates. Similar statements have been issued by financial regulators and practitioners: "The essential problem is that our models - both risk models and econometric models - as complex as they have become, are still too simple to capture the full array of governing variables that drive global economic reality.", Greenspan (2008). "Whenever we make a model of something involving human beings, we are trying to force the ugly stepsister's foot into Cinderella's pretty glass slipper. It doesn't fit without cutting off some essential parts. Models inevitably mask as well as expose risk. You must start with models and then overlay them with common sense and experience.", Derman (2011).

As suggested by Das (2007), the financial system normally focuses on the accuracy of the models used to calculate VaR, often without a detailed assessment of the assumptions incorporated in them. However, a given volatility behavior may lead to wildly different credit VaR estimates under alternative distributional assumptions on returns. Performing the same analysis with different data sources can also produce disparate results, being hard to prefer one to another. An additional limitation of risk modelling is acting as if the processes governing financial markets were immutable "laws" comparable, say, to the laws of physics. On the contrary, in financial markets, time-invariant phenomena, if they exist at all, are the exception rather than the rule. The report concludes that credit risk is even more sensitive than market risk to correlation assumptions, since arbitrary, inaccurate correlation specifications can cause large errors in capital requirements. That is the reason for the interest in research on modelling asset correlation.

Precisely, the crisis has shown the need to have more flexible credit risk models that could easily incorporate the type of changes in correlations that can arise in stressed times. The supervisory standards for managing model risk FRB SR 11-7 refer to accuracy testing, like VaR backtesting, as a required tool for model evaluation. But they also cite that benchmarking to alternative model specification should be an important element of model assessment. Our research strategy has been consistent with this mandate. We have considered four alternative correlation models, different risk factors, and we have compared the forward-looking value-at-risk estimates obtained with corporate bond and CDS 
spread data. The fact that the qualitative results of our analysis have been shown to be robust to these choices makes them reliable, giving more weight to the implied policy recommendations for risk management and supervision.

Our analysis, as well as those of Dullmann et al. (2007), Lopez (2004) make advances in incorporating time-varying asset correlations, crucial parameters for credit risk estimation. But, while Dullmann et al. (2007) concluded that the results obtained from alternative models were very similar to those from the BIS II model, we have shown that the Basel II IRB model did not capture the level of market volatility during the period 2007-2012. In the pre-crisis period (January 2007-April 2007), we indeed obtain similar results to those from Basel II IRB and from the Dullmann study, which covers the period 1998-2004. However, during the crisis period (May 2007-December 2012), the results of the Basel II IRB model are very far from our proposed correlation models. A posteriori it seems quite reasonable to believe that the requirement of capital during the crisis should have been higher than before the crisis, due to increased credit correlations, and we have shown that indeed, the information available in the credit market should have led to significantly higher capital requirements. Having a higher capital requirement when forward-looking correlations indicate an increase in the level of risk could well be a way to avoid "pro-ciclicality", whereby capital goes up when it is too late and banks are resource constrained. The BIS correlation is calibrated to the KMV dataset, which is the standard of the industry and it is based on the asset value of the different firms, which could be less volatile than CDS market data. Furthermore, the forward-looking information provided by the CDS market might incorporate some extra premium by illiquidity, which must have been rather high during the crisis. But it is unlikely that these considerations can explain such large differences between models. ${ }^{30}$

Rather, we consider that a central question of our analysis is to have explored whether the forwardlooking information provided by the derivative credit market is a good proxy of the "real" credit market. Even though the answer is not obvious, it is clear that the "red flags" provided by the derivative market should be incorporated by the regulators when trying to prevent future difficulties. Indeed, if credit spreads at some point signaled an increased probability of an extreme credit situation in market participants, it would be desirable that regulatory and internal risk models would reflect such a situation. It would surely be undesirable, and possibly unfeasible, for regulators to react as drastically as the financial markets, but regulatory capital requirements should reflect market trends as incorporated into derivative credit markets. In any event, stripping the relevant information in credit derivatives to avoid false positives is a challenging issue that deserves further analysis.

Besides these limitations of risk modelling, the conflicts of interest in rating agencies may distort this crucial input of credit risk estimation. Furthermore, regulatory driven securitization with the aim of lowering capital requirements has in the past weakened the effect of market regulation. To summarize, regulation is not easy, but it is clearly important to understand what is happening in the market,

\footnotetext{
${ }^{30}$ The need to revise the BIS II model for capital requirement as also emphasized by Das (2007).
} 
which information is relevant, and how it should be incorporated into regulatory models and into internal credit risk models at financial institutions.

\section{Conclusions and open questions}

We have estimated the time evolution of value at risk and expected shortfall of a global equallyweighted credit portfolio at the time of the financial crisis by performing an extensive simulation exercise that combines a Merton model of the firm with a Vasicek-type correlation model.

The correlation parameters in the Merton model are estimated using the forward-looking information contained in CDS spreads rather than the backward-looking information in historical default rates. Since defaults are very rare events, a very long history is required to obtain a reasonable sample, raising the issue of whether the relationships estimated from the data would be relevant to the corporate world today. It has also been pointed out that a deficient modelling of correlation under stress could have been the cause of the failure of pre-crisis stress tests to detect the vulnerabilities of the financial system [see Oura and Schumacher (2012)]. Our methodology, based on information from credit derivatives, offers a robust forward-looking analysis of credit correlations under a stress scenario. Furthermore, estimates of economic capital from forward-looking information might provide us with relevant information about future systemic adverse shocks.

The estimated correlation models are simulated to obtain sample trajectories for the value of the firm's assets for each CDS issuer. Along a given trajectory, the value of assets is compared with the threshold for default that emerges from the physical probability of default associated to the issuer rating. If default occurs, there is an implied loss, and the portfolio P\&L is computed at each point in time by aggregating losses across all firms in the portfolio. Repeating the exercise for a large number of trajectories, we estimate the portfolio's value at risk and expected shortfall by taking the appropriate quantile of the distribution of $P \& L$ and the average return over the tail.

On the basis of our results for the 2007-2012 period, a single risk factor model seems as a good representation of credit market correlation because of the high inter-sectoral correlations. However, an appropriately chosen second factor provides additional information for risk estimation in stressed times. Yet the overall impression is that the failure of models to predict the crisis was not because they were over-simplified but rather, because they were backward-looking.

We obtain the following results from our analysis: First, our estimates clearly show that there were signs of stress in the credit market prior to the crisis that the financial sector did not appropriately introduce into its internal risk models. Such information was also not used by regulators, with required capital falling well below what had been needed under our VaR estimates. These results justify the increased attention being paid to risk management at the portfolio level, rather than at the level of a single firm, in order to minimize the possibility of an excessive concentration on common sources of 
risk that might derive in future problems for a financial institution. Furthermore, we have provided evidence suggesting that the VaR of a given sector depends not only on the average PD of issuers in that sector but also on their degree of risk heterogeneity (as in Gordy and Lütkebohmert (2013)) . Indeed, our correlation models can anticipate losses derived from risk concentration in credit portfolios. Finally, these qualitative results have been confirmed by using corporate bond return data instead of CDS spreads.

The credit derivative market has a strong speculative component and it is very illiquid, but it has been very good at reflecting the economic circumstances of each moment. So, it is hard to see why the forward-looking information embedded in credit derivatives should lead to capital requirements so much higher than using the Basel II model, as shown in this paper. Such disparate evidence suggests that the calibration of the Basel II function for capital requirement should incorporate changes in credit market expectations. Nevertheless, differences between both approaches over more stable periods might be much less significant.

It would be interesting to obtain VaR estimates for the real risk exposure of the credit market as a whole, instead of assuming an equal exposure to each issuer. Also, our approach could be generalized to incorporate into the correlation models a different volatility for each sector and for each firm, to be estimated from actual data. An even more challenging extension would consider time varying volatilities, levels of debt and rates of growth of the value of assets, following the work of Du et al. (2016). A model calibrated solely to CDS data may have inflated parameters. Thus, it would be interesting to discount from the estimated correlation the effect of market sentiment and use that lower correlation to estimate risk indicators. A preliminary analysis shows that the VIX index and the MSCI indices explain a substantial part of our correlation estimates. Finally, a departure from the Gaussian framework maintained in our analysis could have a sizeable impact on VaR estimates of credit portfolios. These remain as interesting issues for further research.

\section{References}

Bada, O., Liebl, D., et al., 2014. phtt: Panel data analysis with heterogeneous time trends in R. Journal of Statistical Software 59 (i06).

Bai, J., Ng, S., 2002. Determining the number of factors in approximate factor models. Econometrica 70 (1), 191-221.

BCBS, 2006. Basel II: International convergence of capital measurement and capital standards: A revised framework - comprehensive version. Basel Committee on Banking Supervision, Basel.

Black, F., Cox, J. C., 1976. Valuing corporate securities: Some effects of bond indenture provisions. The Journal of Finance 31 (2), 351-367. 
Chamizo, A., Novales, A., 2016a. Credit risk decomposition for asset allocation. Journal of Financial Transformation (43), 117-123.

Chamizo, A., Novales, A., 2016b. Looking through systemic risk: Determinants, stress testing and market value. SSRN (2842580).

Crosbie, P., 1999. Global correlation factor. Moody's KMV Company.

Crosbie, P., 2003. Modeling default risk. Moody's KMV Company.

Daníelsson, J., Jorgensen, B. N., Samorodnitsky, G., Sarma, M., de Vries, C. G., 2013. Fat tails, var and subadditivity. Journal of econometrics 172 (2), 283-291.

Das, S. R., 2007. Basel II: Correlation related issues. Journal of Financial Services Research 32 (1-2), $17-38$.

Derman, E., 2011. Metaphors, models \& theories. The Quarterly Journal of Finance 1 (01), 109-126.

Du, D., Elkamhi, R., Ericsson, J., 2016. Time-varying asset volatility and the credit spread puzzle. Journal of Finance. Forthcoming.

Duffie, D., Singleton, K. J., 1999. Modeling term structures of defaultable bonds. Review of Financial studies 12 (4), 687-720.

Dullmann, K., Scheicher, M., Schmieder, C., 2007. Asset correlations and credit portfolio risk - an empirical analysis. Discussion Paper Series 2: Banking and Financial Studies. Deutsche Bundesbank 13.

Elkamhi, R., Ericsson, J., Parsons, C. A., 2012. The cost and timing of financial distress. Journal of Financial Economics 105 (1), 62-81.

Ericsson, J., Jacobs, K., Oviedo, R., 2009. The determinants of credit default swap premia. Journal of Financial and Quantitative Analysis 44 (01), 109-132.

Erlenmaier, U., Gersbach, H., 2013. Default correlations in the Merton model. Review of Finance 18 (5), 1775-1809.

FED, 2011. Supervisory guidance on model risk management. Board of Governors of the Federal Reserve System, Office of the Comptroller of the Currency, SR Letter, 11-7.

Gianfrancesco, I., Curcio, D., Malinconico, A., 2011. Investigating implied asset correlation and capital requirements: empirical evidence from the italian banking system. Banks and Bank Systems 6 (2).

Goldberg, J., Nozawa, Y., 2018. Liquidity supply and demand in the corporate bond market. Federal Reserve Board, manuscript.

Gordy, M. B., Lütkebohmert, E., 2013. Granularity adjustment for regulatory capital assessment. International Journal of Central Banking 9 (3), 33-70.

Greenspan, A., 2008. We will never have a perfect model of risk. Financial Times.

Huang, J.-Z., Huang, M., 2012. How much of the corporate-treasury yield spread is due to credit risk? The Review of Asset Pricing Studies 2 (2), 153-202.

Hull, J., Predescu, M., White, A., 2010. The valuation of correlation-dependent credit derivatives using a structural model. The Journal of Credit Risk 6 (3), 99.

Hull, J., White, A., 2001. The general Hull-White model and supercalibration. Financial Analysts 
Journal, 34-43.

Jacobs, M., 2011. Empirical implementation of a 2-factor structural model for loss-given-default. Journal of Financial Transformation 31 (4), 31-43.

Karagozoglu, A. K., Jacobs, M., 2016. Measuring credit risk: CDS spreads vs. credit ratings. Journal of Risk Finance 17 (2), 194-217.

Kendall, M., Stuart, A., 1977. The advanced theory of statistics. vol. 1: Distribution theory. London: Griffin, 1977, 4th ed. 1.

Kinateder, H., 2016. Basel II versus III: a comparative assessment of minimum capital requirements for internal model approaches. Journal of Risk 18 (3).

Kinateder, H., Wagner, N., 2017. Quantitative easing and the pricing of emu sovereign debt. The Quarterly Review of Economics and Finance 66, 1-12.

Lando, D., 1998. On Cox processes and credit risky securities. Review of Derivatives Research 2 (2-3), 99-120.

Leland, H. E., 2004. Predictions of default probabilities in structural models of debt. Journal of Investement Management 2, 5-20.

Lopez, J. A., 2004. The empirical relationship between average asset correlation, firm probability of default, and asset size. Journal of Financial Intermediation 13 (2), 265-283.

Markit, 2008. Markit.com user guide. Version 14.3.

Markit, 2012. Markit.com user guide CDS \& bonds. Version 16.

McGinty, L., Beinstein, E., Ahluwalia, R., Watts, M., 2004. Credit correlation: A guide. Tech. rep., JP Morgan.

Merton, R. C., 1974. On the pricing of corporate debt: The risk structure of interest rates. The Journal of Finance 29 (2), 449-470.

Novales, A., Garcia-Jorcano, L., 2018. Backtesting extreme value theory models of expected shortfall. Quantitative Finance (to appear) published online, 1-27.

Ou, S., Chiu, D., Wen, B., Metz, A., 2013. Annual default study: Corporate default and recovery rates, 1920-2012. Investors Service, Data Report, February 15, 2013, 1-64.

Oura, H., Schumacher, L. B., 2012. Macrofinancial stress testing-principles and practices. International Monetary Fund Policy Paper.

Schönbucher, P. J., 2000. Factor models for portofolio credit risk. Tech. rep., Bonn Econ Discussion Papers.

Strebulaev, I. A., 2007. Do tests of capital structure theory mean what they say? The Journal of Finance 62 (4), 1747-1787.

Tarashev, N., Zhu, H., 2008. The pricing of correlated default risk: Evidence from the credit derivatives market. Discussion Paper Series 2: Banking and Financial Studies. Deutsche Bundesbank 09.

Vasicek, O., 2002. The distribution of loan portfolio value. Risk 15 (12), 160-162.

Zhou, C., 2001. An analysis of default correlations and multiple defaults. The Review of Financial Studies 14 (2), 555-576. 


\section{Appendix}

Table 1: Distribution of firms in the sample by industry and region: 2006-2012

\begin{tabular}{|c|c|c|c|c|c|c|c|c|c|c|c|c|c|}
\hline Industry/Region & AF & AS & CA & EE & EU & IN & LA & ME & NA & OC & OS & SU & T \\
\hline \hline Basic materials (BM) & & 14 & & & 17 & 1 & 2 & & 33 & 2 & & & 69 \\
\hline Consumer goods (CG) & & 26 & & & 33 & & & & 54 & 2 & & & 115 \\
\hline Consumer services (CS) & 1 & 20 & & & 35 & & 1 & & 52 & 3 & & & 112 \\
\hline Energy (EN) & & 7 & 1 & & 6 & & 2 & & 33 & 1 & & & 50 \\
\hline Financials (FN) & & 30 & & 1 & 69 & 1 & 1 & & 61 & 10 & & & 173 \\
\hline Government (GOV) & 4 & 20 & 1 & 13 & 14 & 2 & 12 & 5 & 1 & & & 1 & 73 \\
\hline Health Care (HC) & & & & & 4 & & & 1 & 24 & & & & 29 \\
\hline Industrials (IND) & & 28 & & & 30 & 1 & & & 46 & 4 & 1 & 1 & 111 \\
\hline Technology (TECH) & & 11 & & & 5 & & & & 16 & & 1 & & 33 \\
\hline Telecommunication services (TEL) & & 9 & & 1 & 20 & & & & 14 & 3 & & & 47 \\
\hline Utilities (UTI) & & 13 & & & 27 & & & 1 & 27 & & 1 & & 69 \\
\hline Total (T) & 5 & 178 & 2 & 15 & 260 & 5 & 18 & 7 & 361 & 25 & 3 & 2 & 881 \\
\hline
\end{tabular}

Note: The table shows the distribution of firms in the sample across regions and sectors. AF:Africa, AS: Asia, CA: Caribbean.

E.E.: Eastern Europe, EU: Europe, IN: India, LA: Latin America, ME: Middle East, NA: North America, OC: Oceania, OF:

Offshore, SU:Supra, T: Total. Offshore and Supranation are geographic categories in Markit database. Supranation refers to CDS from public organizations.

Table 2: Industry-rating distribution of firms in the sample: June 30, 2006

\begin{tabular}{|c|c|c|c|c|c|c|c|c|c|c|c|c|}
\hline Rating/Industry & BM & CG & CS & EN & F & G & HC & I & TH & TL & UT & T \\
\hline \hline AAA & & 2 & & & 6 & 6 & 1 & & & & & 15 \\
\hline AA & & 6 & 6 & 6 & 44 & 6 & 5 & 1 & 2 & 3 & 13 & 92 \\
\hline A & 21 & 27 & 21 & 12 & 74 & 30 & 5 & 32 & 9 & 20 & 22 & 273 \\
\hline BBB & 30 & 53 & 54 & 22 & 42 & 7 & 11 & 54 & 8 & 17 & 24 & 322 \\
\hline BB & 11 & 23 & 20 & 10 & 6 & 17 & 6 & 16 & 10 & 3 & 7 & 129 \\
\hline B & 7 & 3 & 11 & & 1 & 6 & 1 & 7 & 3 & 3 & 3 & 45 \\
\hline CCC & & 1 & & & & 1 & & 1 & 1 & 1 & & 5 \\
\hline Total & 69 & 115 & 112 & 50 & 173 & 73 & 29 & 111 & 33 & 47 & 69 & 881 \\
\hline
\end{tabular}

Note: The table shows the distribution of firms with a given rating in each sector at the beginning of the sample. BM: Basic materials, CG: Consumer goods, CS: Consumer services, EN: Energy , F: Financials, G: Government, HC: Health care, I: Industrials, TH: Technology, TL:Telecommunication services, UT: Utilities and T: Total. 
Table 3: Industry-rating distribution of firms in the sample: June 30, 2012

\begin{tabular}{|c|c|c|c|c|c|c|c|c|c|c|c|c|c|}
\hline Rating/Industry & BM & CG & CS & EN & F & G & HC & I & TH & TL & UT & T & PD \\
\hline \hline AAA & & & & & & 2 & & & & & & 2 & $0.01 \%$ \\
\hline AA & & 5 & 8 & 5 & 18 & 7 & 3 & & 2 & 3 & 9 & 60 & $0.03 \%$ \\
\hline A & 18 & 27 & 13 & 12 & 84 & 22 & 10 & 30 & 7 & 18 & 18 & 259 & $0.07 \%$ \\
\hline BBB & 31 & 48 & 57 & 28 & 57 & 25 & 7 & 50 & 13 & 18 & 34 & 368 & $0.20 \%$ \\
\hline BB & 18 & 21 & 16 & 5 & 6 & 11 & 4 & 23 & 8 & 4 & 7 & 123 & $1.14 \%$ \\
\hline B & 2 & 11 & 15 & & 4 & 5 & 5 & 7 & 2 & 2 & 1 & 54 & $4.04 \%$ \\
\hline CCC & & 3 & 3 & & 4 & 1 & & 1 & 1 & 2 & & 15 & $13.76 \%$ \\
\hline Total & 69 & 115 & 112 & 50 & 173 & 73 & 29 & 111 & 33 & 47 & 69 & 881 & \\
\hline
\end{tabular}

Note: The table shows the distribution of firms with a given rating in each sector at the end of the sample. BM: Basic materials, CG: Consumer goods, CS: Consumer services, EN: Energy , F: Financials, G: Government, HC: Health care, I: Industrials, TH: Technology, TL:Telecommunication services, UT: Utilities and T: Total. PD: Probability of default. Data taken from Exhibit 23: 'Annual Credit Loss Rates by Letter Rating, 1982-2012*' in Ou et al. (2013). The AAA default probability has been rounded up to $0.01 \%$.

Table 4: Main features of one-factor correlation models

\begin{tabular}{|c|c|c|c|c|}
\hline Model name & Factor & Correlation parameter & Factor equation & Correlation parameter $(r)$ \\
\hline \hline Basel II IRB & Global & PD dependent & $v_{i, 1}=r_{P D_{i}} X+\sqrt{1-r_{P D_{i}}^{2}} \xi_{i}$ & $\left.r_{P D_{i}}=\sqrt{0.24-0.12\left(1-e^{-50 P D_{i}}\right.}\right)$ \\
\hline Market & Global & Firm specific & $v_{i, 1}=r_{i} X+\sqrt{1-r_{i}^{2}} \xi_{i}$ & $r_{i}=\operatorname{Corr}\left(\Delta M D D_{i}, \Delta X\right)$ \\
\hline Sectorial Market & Global & Sector specific & $v_{i, 1}=r_{s} X+\sqrt{1-r_{s}^{2}} \xi_{i}$ & $r_{s}=\operatorname{med}_{i}\left[\operatorname{Corr}\left(\Delta M D D_{i}, \Delta X\right)\right]$ \\
\hline Sectorial & Sector & Sector specific & $v_{i, 1}=r_{s} X_{s}+\sqrt{1-r_{s}^{2}} \xi_{i}$ & $r_{s}=\operatorname{med}_{i}\left[\operatorname{Corr}\left(\Delta M D D_{i}, \Delta M X_{s}\right)\right]$ \\
\hline Individual Sectorial & Sector & Firm specific & $v_{i, 1}=r_{i} X_{s}+\sqrt{1-r_{i}^{2}} \xi_{i}$ & $r_{i}=\operatorname{Corr}\left(\Delta M D D_{i}, \Delta X_{s}\right)$ \\
\hline
\end{tabular}

Note: The table shows the main characteristics of one-factor correlation models. The last column shows the expressions used in the paper to estimate the correlation parameters.

Table 5: Correlations with global and sectorial risk factors

\begin{tabular}{|c|c|c|c|c|c|c|c|c|}
\hline & \multicolumn{9}{|c|}{ correlations with Global factor } & \multicolumn{3}{c|}{ Correlations with Sectorial factor } \\
\hline Sector & mean & median & $1 \mathrm{Q}$ & $3 \mathrm{Q}$ & mean & median & $1 \mathrm{Q}$ & $3 \mathrm{Q}$ \\
\hline \hline BM & 0.43 & 0.46 & 0.26 & 0.46 & 0.43 & 0.46 & 0.26 & 0.46 \\
\hline CG & 0.41 & 0.43 & 0.26 & 0.58 & 0.41 & 0.43 & 0.26 & 0.58 \\
\hline CS & 0.41 & 0.44 & 0.23 & 0.44 & 0.41 & 0.44 & 0.23 & 0.44 \\
\hline EN & 0.44 & 0.47 & 0.32 & 0.47 & 0.44 & 0.47 & 0.32 & 0.47 \\
\hline FN & 0.44 & 0.46 & 0.28 & 0.46 & 0.44 & 0.46 & 0.28 & 0.46 \\
\hline GOV & 0.42 & 0.45 & 0.26 & 0.45 & 0.42 & 0.45 & 0.26 & 0.45 \\
\hline HC & 0.32 & 0.33 & 0.10 & 0.33 & 0.32 & 0.33 & 0.10 & 0.33 \\
\hline IND & 0.42 & 0.44 & 0.24 & 0.44 & 0.42 & 0.44 & 0.24 & 0.44 \\
\hline TECH & 0.34 & 0.34 & 0.13 & 0.34 & 0.34 & 0.34 & 0.13 & 0.34 \\
\hline TEL & 0.44 & 0.46 & 0.25 & 0.46 & 0.44 & 0.46 & 0.25 & 0.46 \\
\hline UTI & 0.39 & 0.42 & 0.23 & 0.42 & 0.39 & 0.42 & 0.23 & 0.42 \\
\hline
\end{tabular}

Note: Summary statistics for correlations between firms and the Global and Sectorial risk factors. Q1 and Q3 are the first and third cuartiles. The Global risk factor is estimated as the first principal component across all the issuers in the sample. The Sectorial risk factor is estimated as the first principal component acros the issuers in each sector. 
Cuadro 6: Two-factor models and correlations between any two firms

\begin{tabular}{|c|c|c|c|}
\hline & & \multicolumn{2}{|c|}{ Correlation between two firms: } \\
\hline & Model & From the same sector $(s, s)$ & From different sectors $(s, z)$ \\
\hline Market & $\nu_{i}=r_{i, X} X+r_{i, Z} Z+\sqrt{1-r_{i, X}^{2}-r_{i, Z}^{2}} \xi_{i}$ & $r_{i, X} r_{j, X}+r_{i, Z} r_{j, Z}$ & $r_{i, X} r_{j, X}+r_{i, Z} r_{j, Z}$ \\
\hline Sectorial Market & $\nu_{i}=r_{s, X} X+r_{s, Z} Z+\sqrt{1-r_{s, X}^{2}-r_{i, Z}^{2}} \xi_{i}$ & $r_{s, X}^{2}+r_{s, Z}^{2}$ & $r_{s, X} r_{z, X}+r_{s, Z} r_{z, Z}$ \\
\hline Sectorial & $\nu_{i}=r_{s, X_{s}} X_{s}+r_{s, Z} Z+\sqrt{1-r_{s, X_{s}}^{2}-r_{i, Z}^{2}} \xi_{i}$ & $r_{s, X_{s}}^{2}+r_{s, Z}^{2}$ & $r_{s, X_{s}} r_{z, X} \omega_{X, s, z}+r_{s, Z} r_{z, Z}$ \\
\hline Individual Sectorial & $\nu_{i}=r_{i, X_{s}} X_{s}+r_{i, Z} Z+\sqrt{1-r_{i, X_{s}}^{2}-r_{i, Z}^{2}} \xi_{i}$ & $r_{i, X_{s}} r_{j, X}+r_{i, Z} r_{j, Z}$ & $r_{i, X_{s}} r_{j, X} \omega_{X, s, z}+r_{i, Z} r_{j, Z}$ \\
\hline
\end{tabular}

Note: Two-factor correlation models. The last two columns show the correlations for any two firms in the same sector or in different sectors. 
Figure 10.1: Average probability of default, by sector. 2006-2012

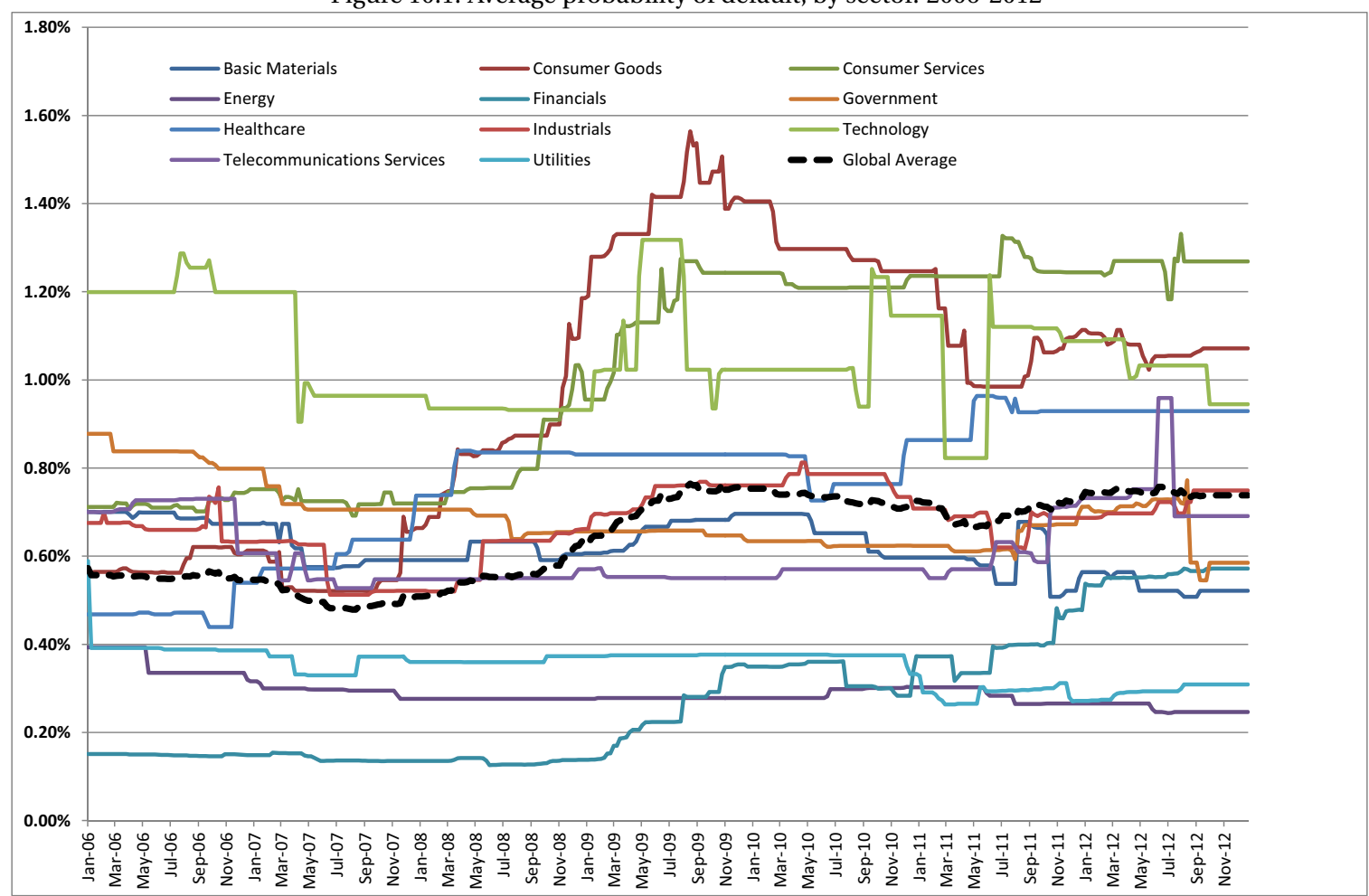

Note: Average probability of default across firms in each sector. These are physical probabilities of default estimated from Moody's ratings. 
Figure 10.2: Median intra-sector asset correlation: 2007-2012

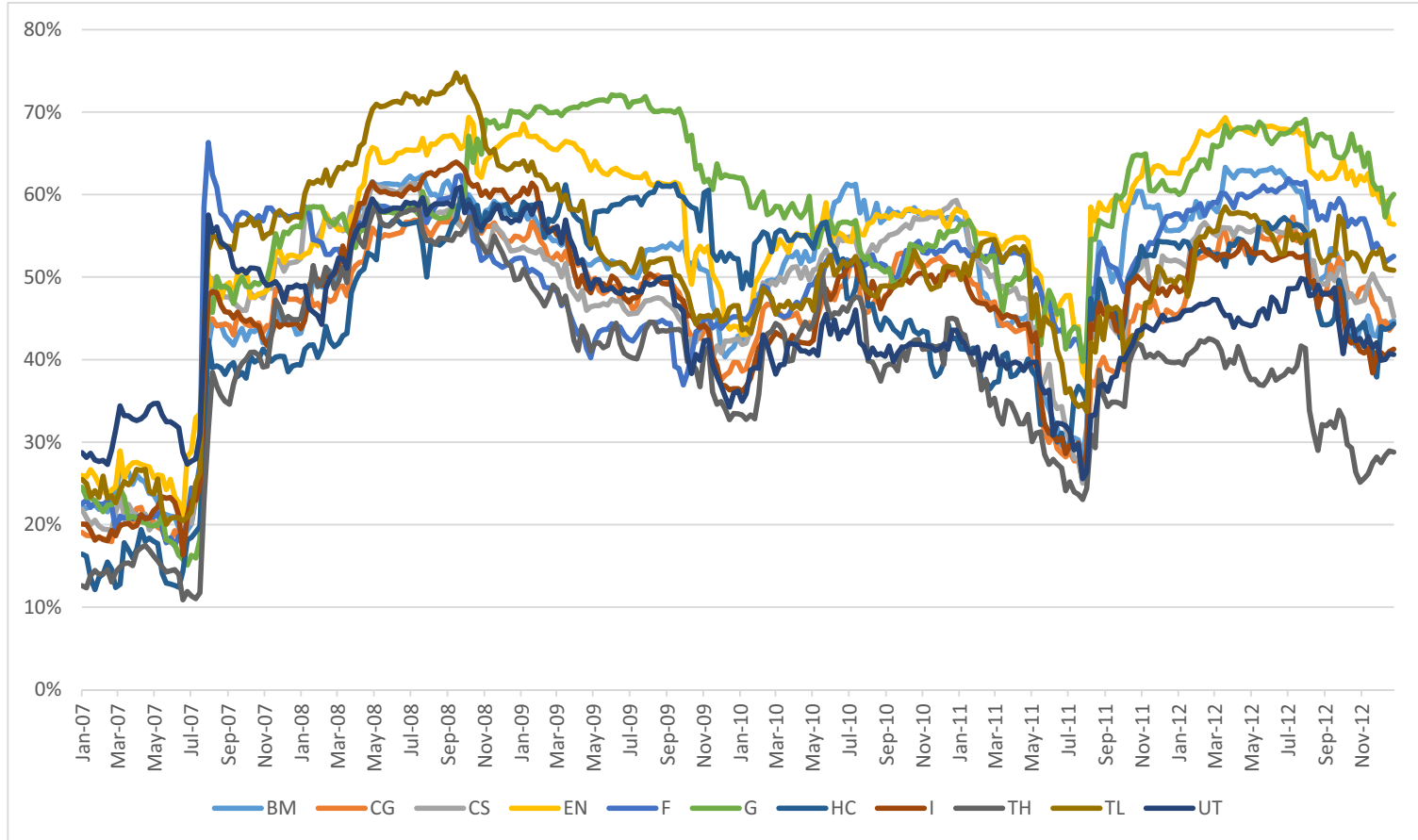

Note: Time evolution of median asset correlations for firms in each sector. BM: Basic materials, CG: Consumer goods, CS: Consumer services, EN: Energy, F: Financials, G: Government, HC: Health care, I: Industrials, TH: Technology, TL:Telecommunication services, UT: Utilities. 
Figure 10.3: Inter-sector correlation with the financial sector: 2007-2012

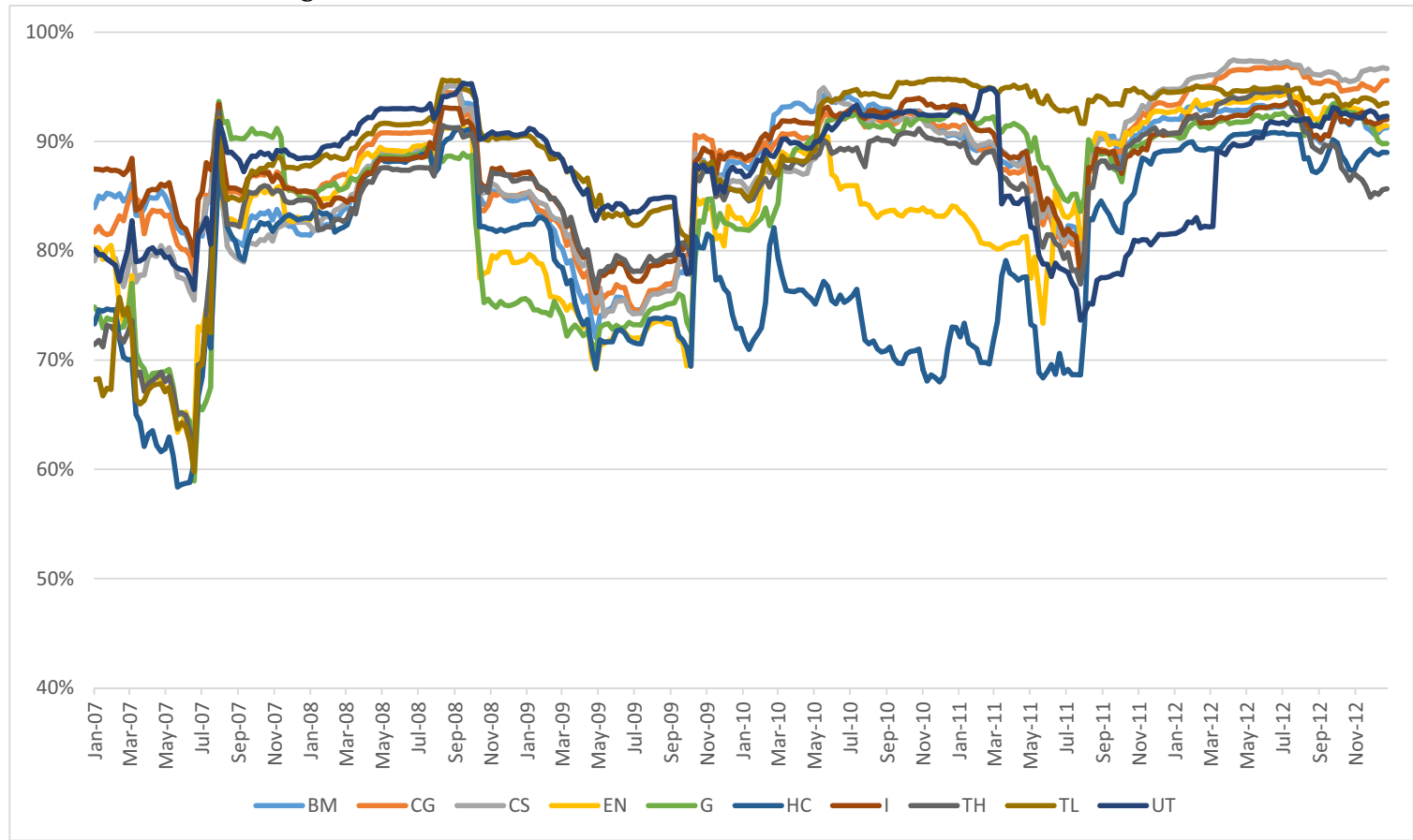

Note: Time evolution of the median asset correlation between each sector and the financial sector. BM: Basic materials, CG: Consumer goods, CS: Consumer services, EN: Energy, F: Financials, G: Government, HC: Health care, I: Industrials, TH: Technology, TL:Telecommunication services, UT: Utilities. 
Figure 10.4: Inter-sector correlation with the utilities sector: 2007-2012

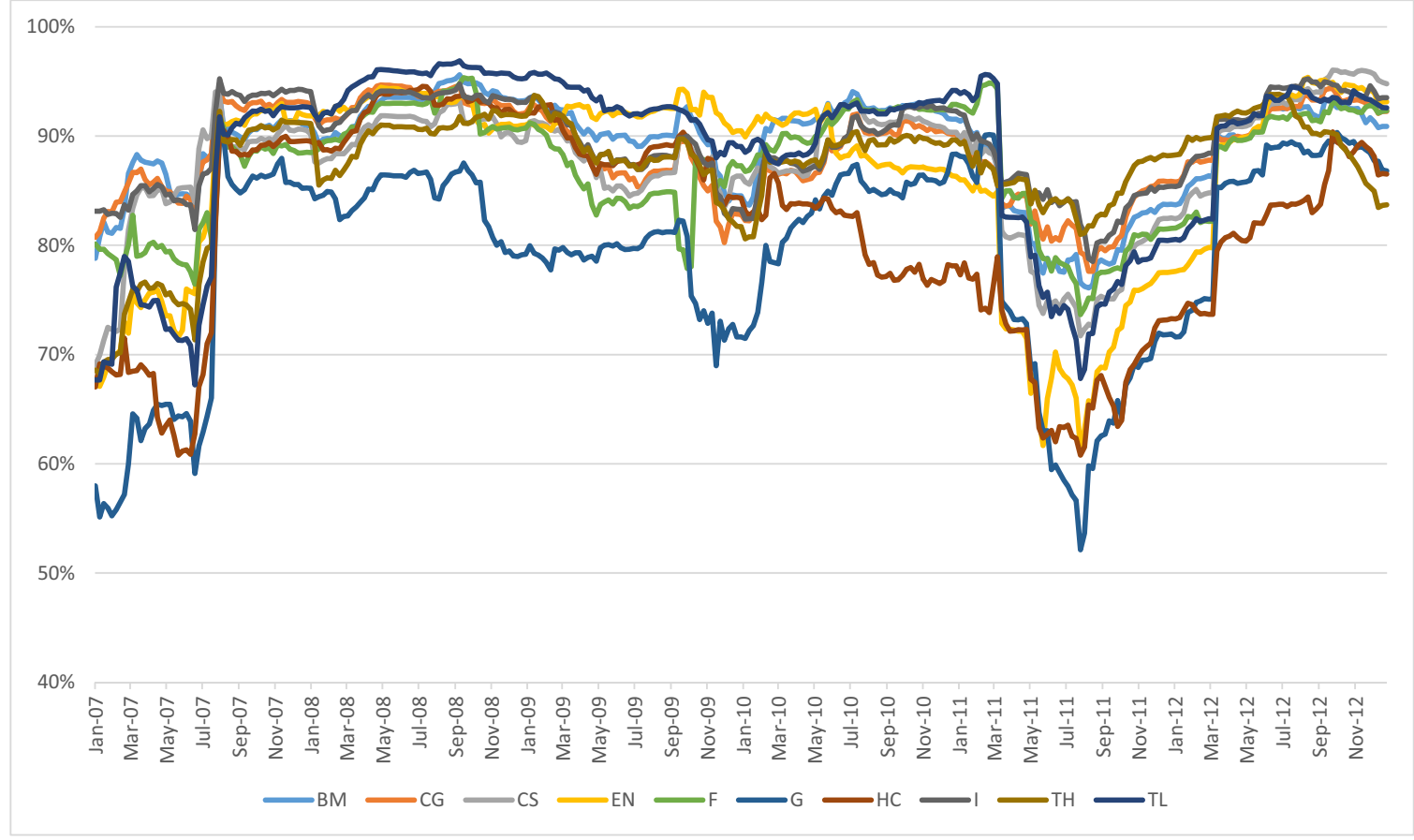

Note: Time evolution of the median asset correlation between each sector and the utilities sector. BM: Basic materials, CG: Consumer goods, CS: Consumer services, EN: Energy, F: Financials, G: Government, HC: Health care, I: Industrials, TH: Technology, TL:Telecommunication services, UT: Utilities.

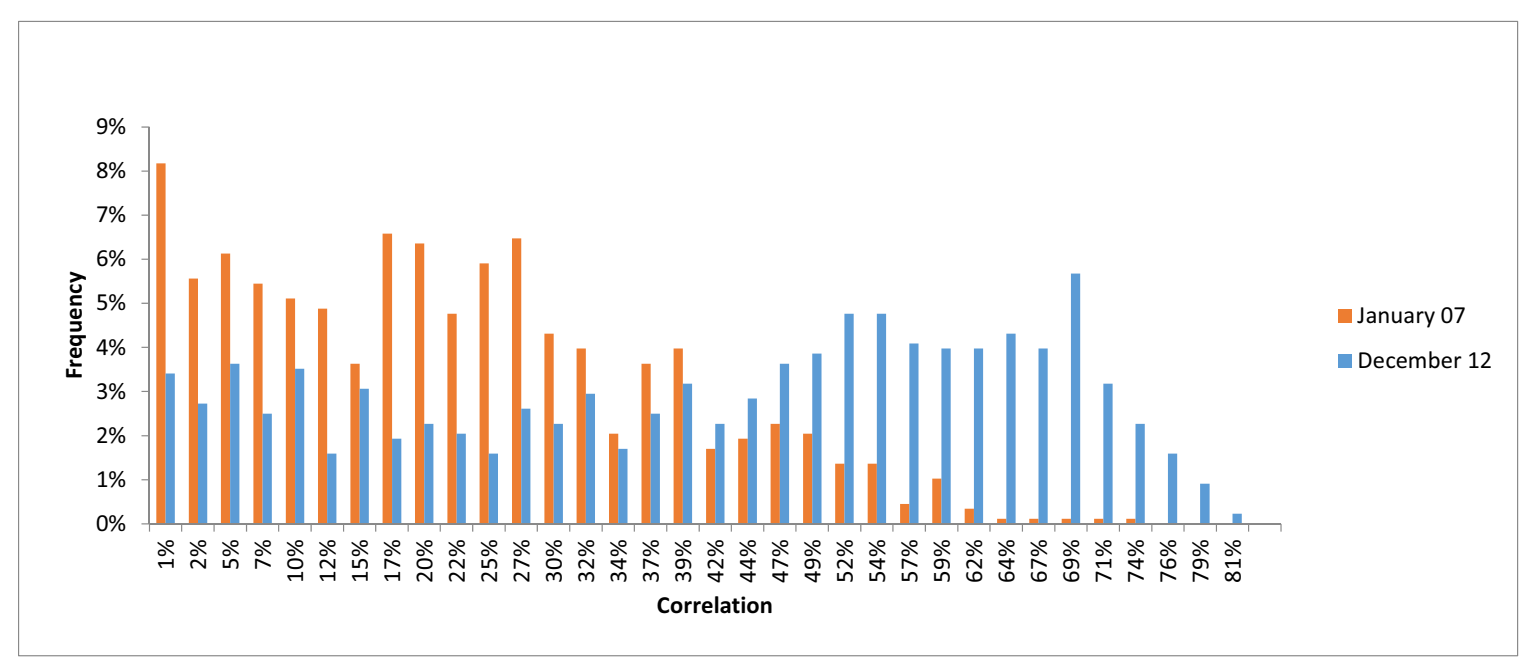

Note: The figure shows the histogram of 881 asset correlations at the beginning and at the end of the sample (2007-2012). 
Figure 10.6: VaR estimates with different correlation models: 2007-2012

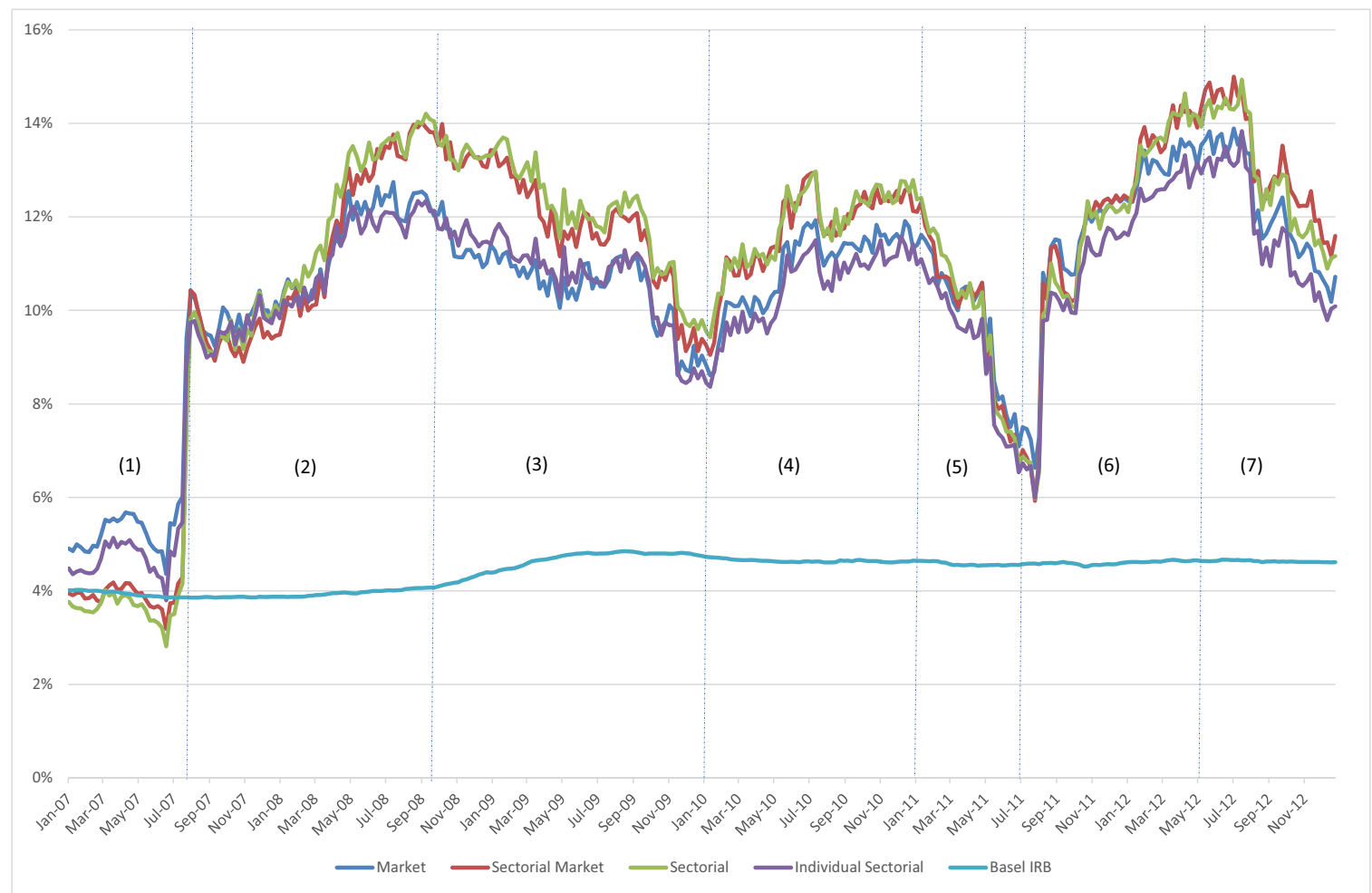

Note: VaR estimates under one-factor correlation models: Basel II, Market model, Sectorial Market model, Sectorial model, Individual Sectorial model.

Phases: (1) Subprime crisis, (2), Lehman default, (3) US stimulus act, (4) Eurozone crisis, (5) EU measures, (6) US rating downgrade, and (7) Draghi measures. 
Figure 10.7: VaR estimates with different correlation models, excluding the Government and Financial sectors

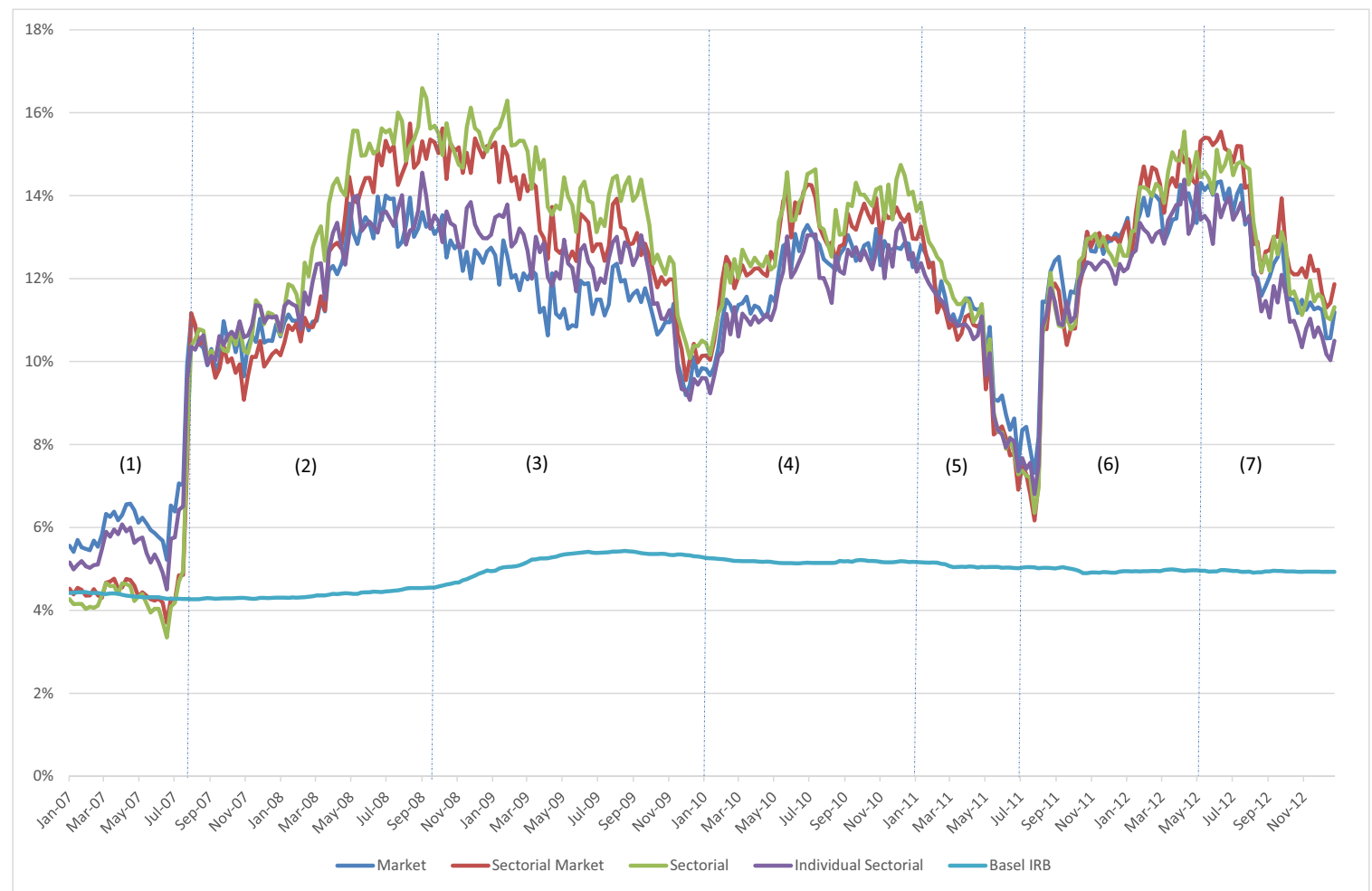

Note: VaR estimates under one-factor correlation models: Basel II, Market model, Sectorial Market model, Sectorial model, Individual Sectorial model, excluding the Government and Financial sectors.

Phases: (1) Subprime crisis, (2), Lehman default, (3) US stimulus act, (4) Eurozone crisis, (5) EU measures, (6) US rating downgrade, and (7) Draghi measures. 
Figure 10.8: Median asset correlation for the portfolio of 45 CDX Investment Grade firms

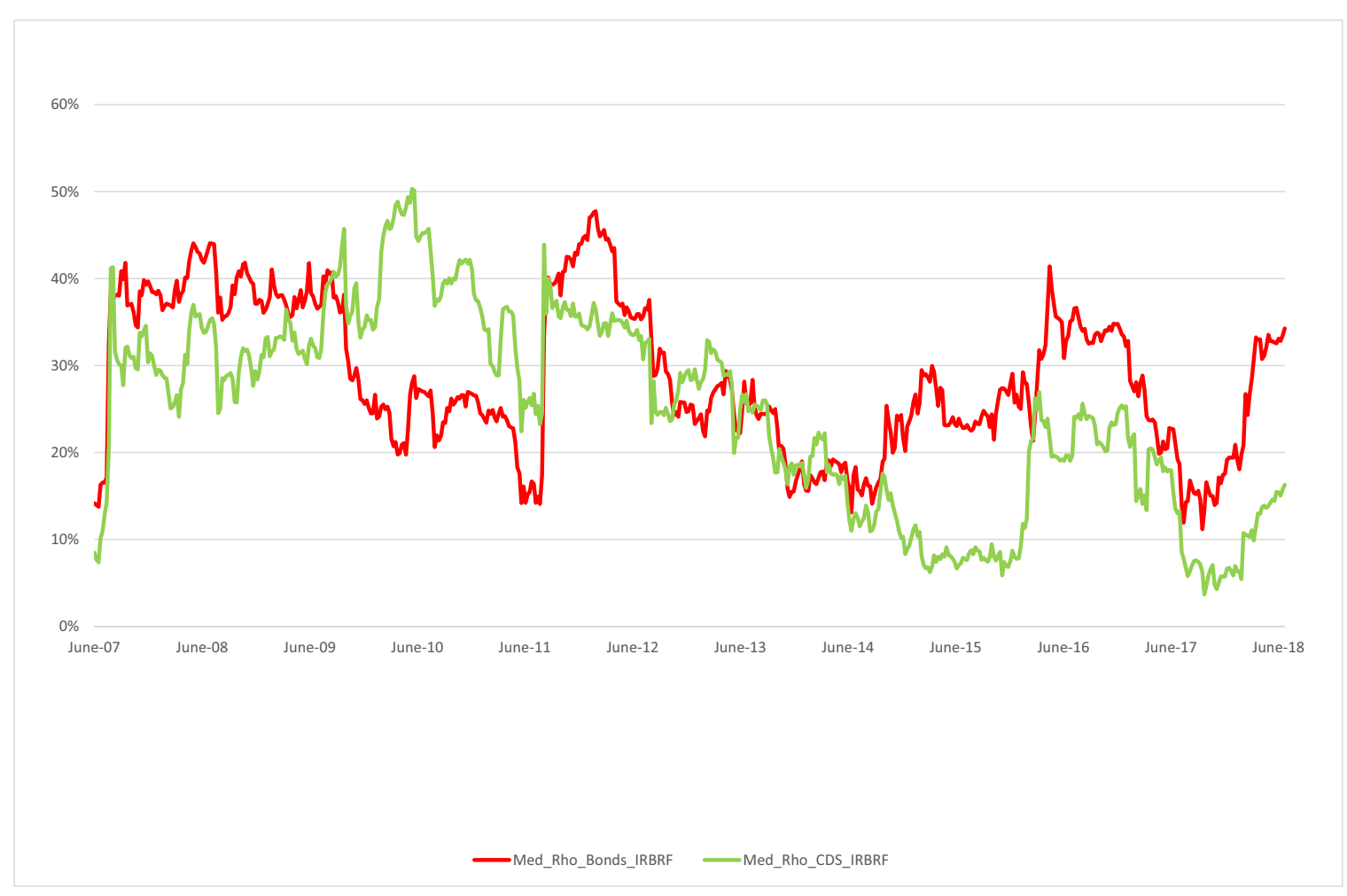

Note: The graph shows the median asset correlation for the sample of 45 CDX Investment Grade firms. The red line shows the median asset correlation estimated from corporate bond data. The green line shows the median asset correlation estimated from CDS data. 
Figure 10.9: VaR estimates or the portfolio of 45 CDX Investment Grade firms

$10 \%$

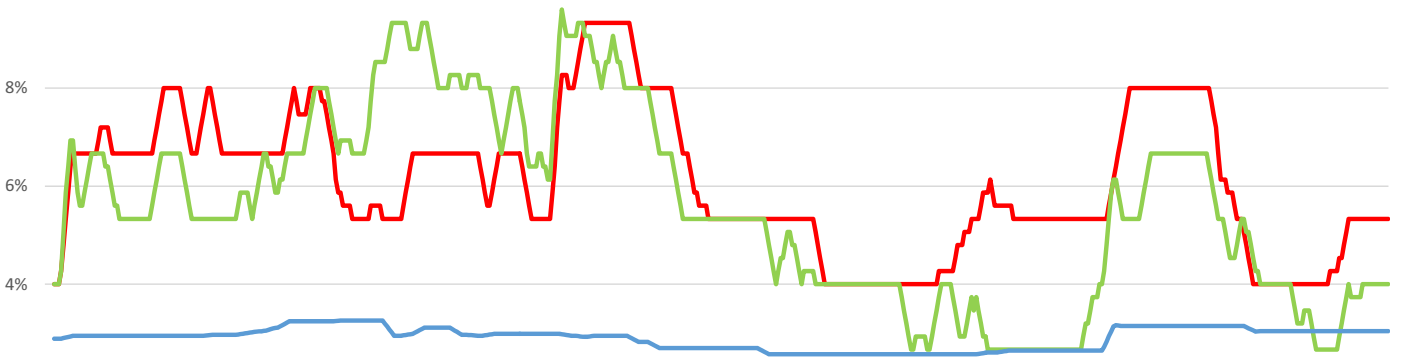

$0 \%$
June-07 June-08 June-09 June-10 June-11 June-12 09

- Bonds_IBRF CDS_IBRF Basel II

Note: The graph shows the time evolution of VaR estimates for the portfolio of 45 CDX Investment Grade firms using the Market model. The red line shows VaR estimates using the asset correlations obtained from corporate bond data. The green line shows VaR estimates using the asset correlations obtained from CDS data. The blue line are the VaR estimates from the Basel II model. 
Figure 10.10: ES estimates with different models: 2007-2012 excluding the Government and Financial sectors

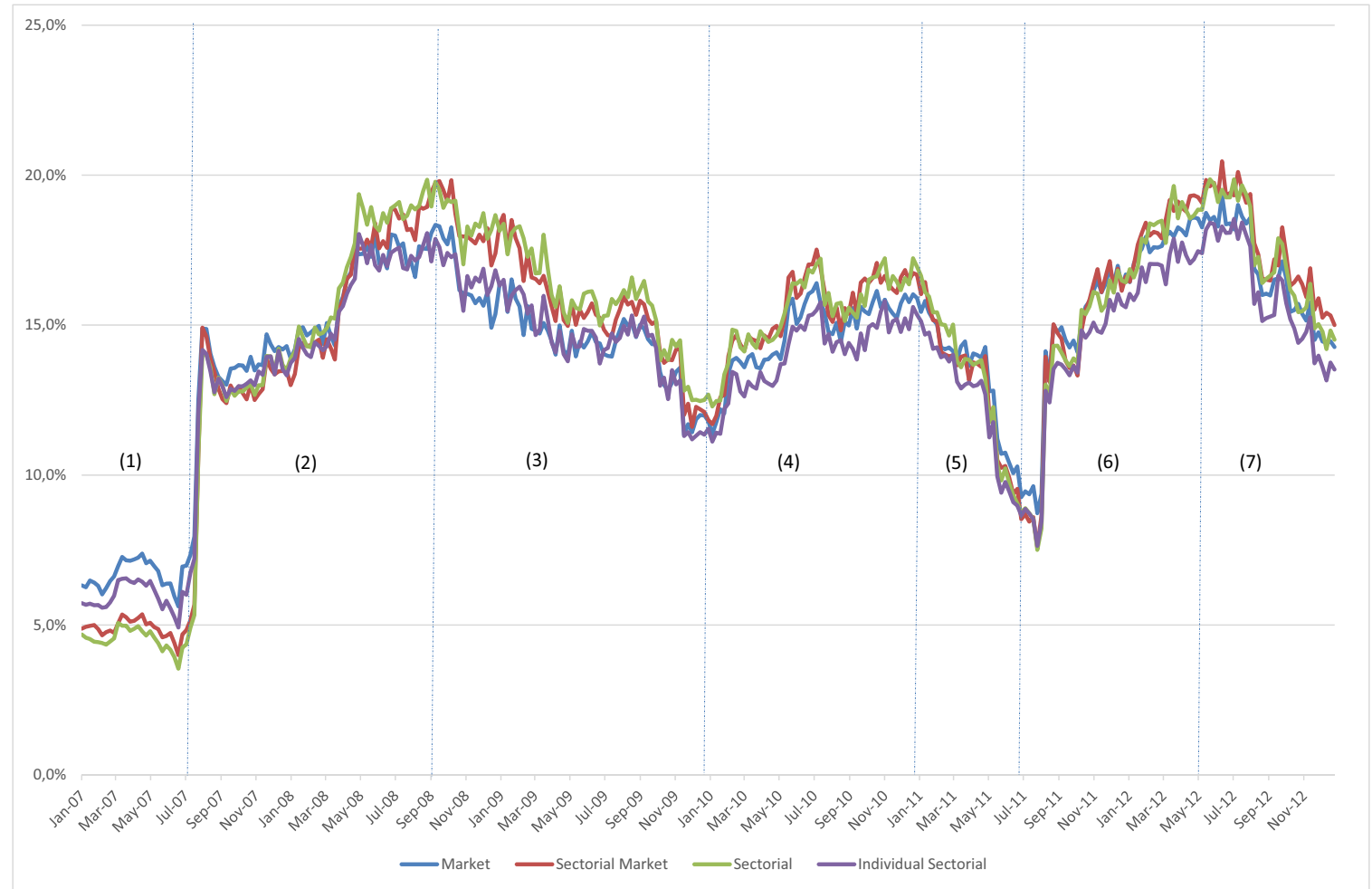

Note: ES estimates under one-factor correlation models: Basel II, Market model, Sectorial Market model, Sectorial model, Individual Sectorial model, excluding the Government and Financial sectors.

Phases: (1) Subprime crisis, (2), Lehman default, (3) US stimulus act, (4) Eurozone crisis, (5) EU measures, (6) US rating downgrade, and (7) Draghi measures. 
Figure 10.11: Impulse responses
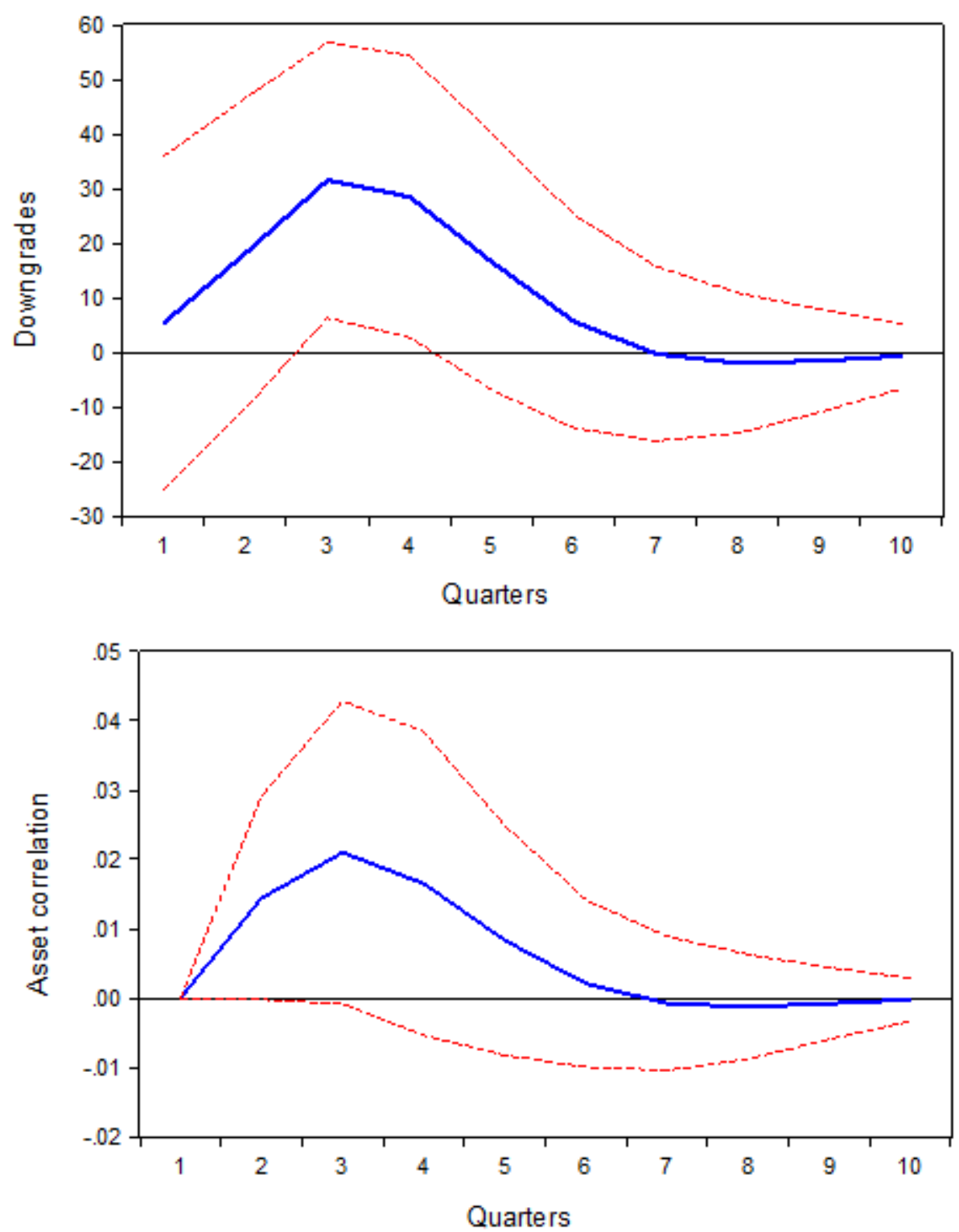

Note: The first graph shows the impulse response function of downgrades to a shock in asset correlation. The second graph shows the impulse responses of asset correlation to a shock in downgrades. The units of the horizontal axis are quarters. Impulse responses are obtained with the Choleski decomposition of the matrix of innovations in a vector autoregression of order two, estimated with quarterly data. 
Figure 10.12: VaR estimates using VIX as the second risk factor

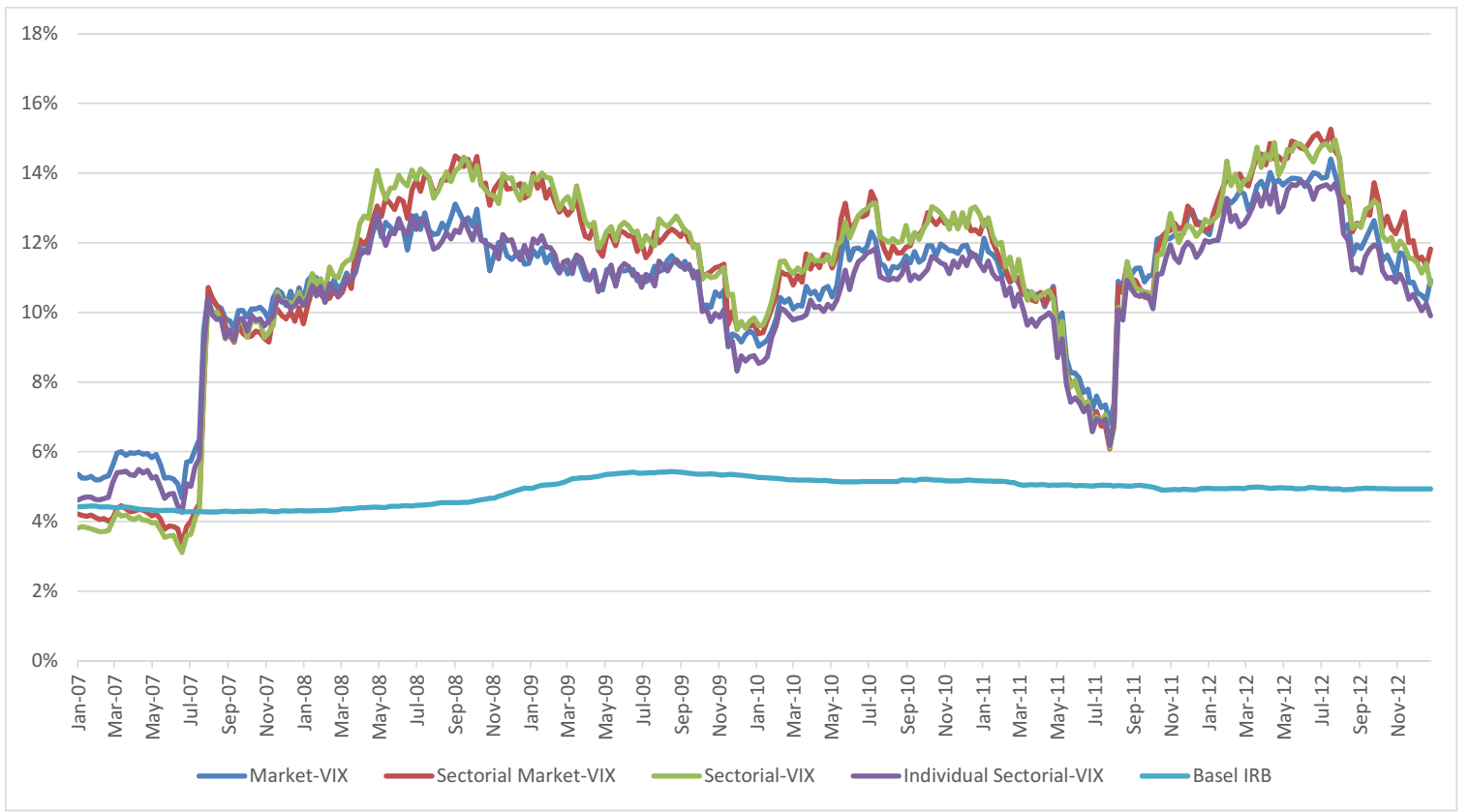

Note: VaR estimates from the one-factor Basel II model and two-factor correlation models, using VIX as the second risk factor: Market model, Sectorial Market model, Sectorial model, Individual Sectorial model.

Figure 10.13: Difference between VaR estimates from similar two- and one-factor models

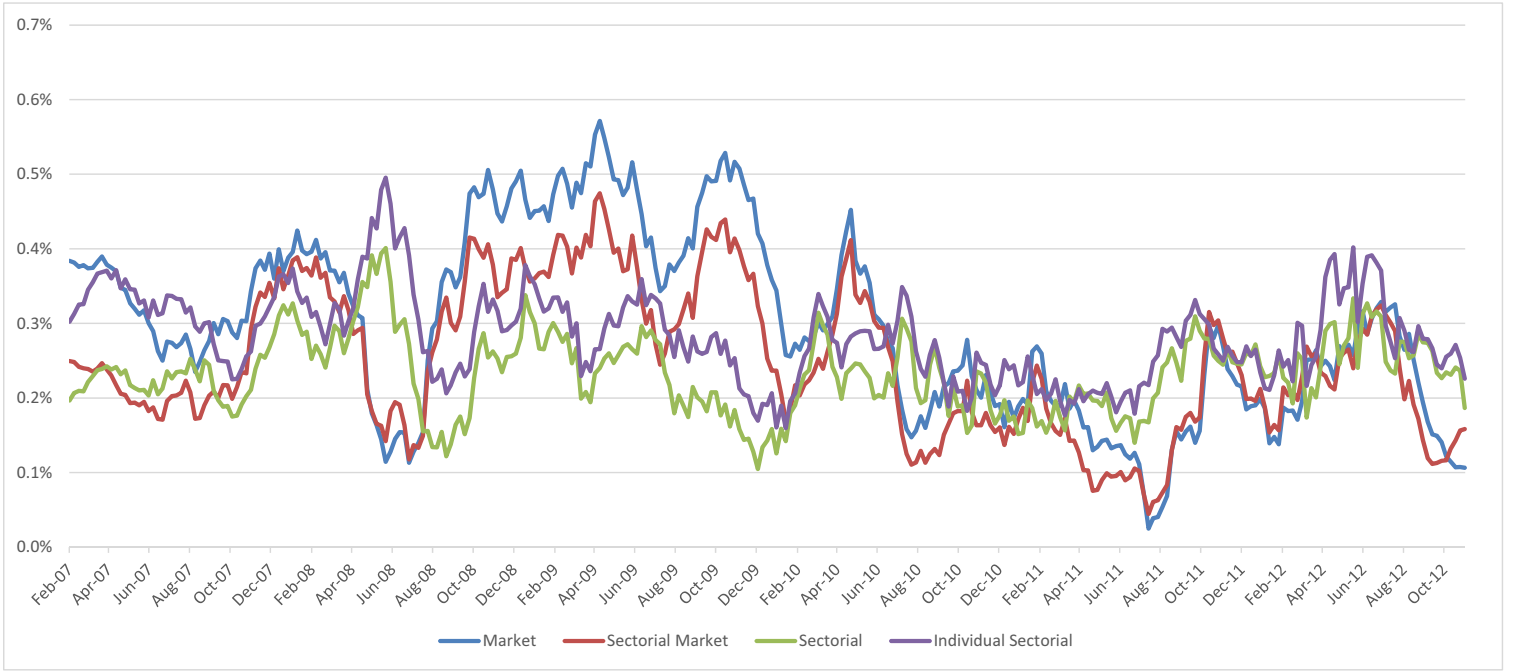

Note: The graph shows the differences between VaR estimates from two- and one-factor models (Market model (blue line), Sectorial market model (red line), Sectorial model (green line), and Individual Sectorial model (purple line). Each line shows the 3-month moving average of such difference for a given correlation model. 
Figure 10.14: VaR estimates from alternative two-factor correlation models

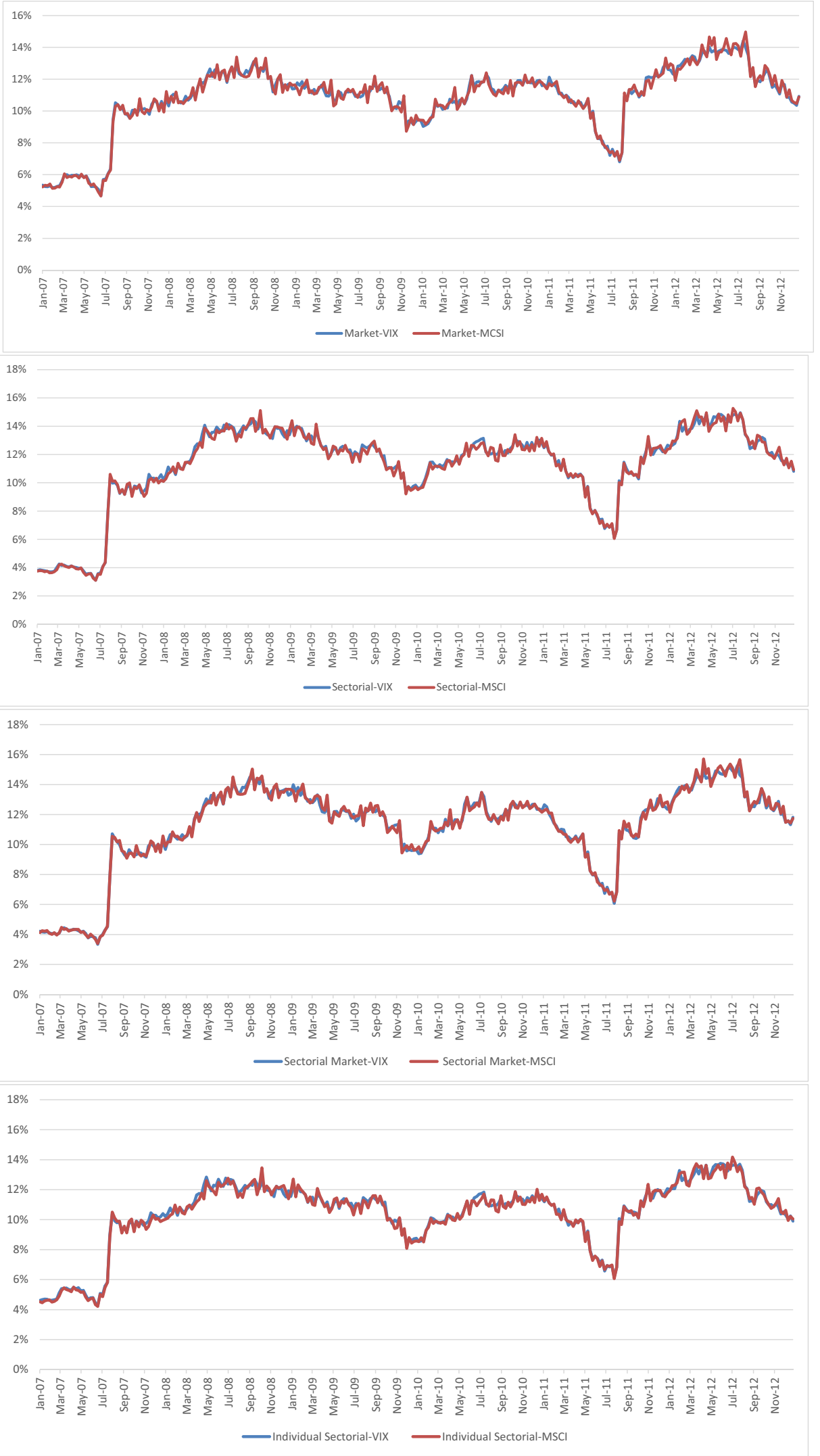

Note: Each graph displays VaR estimates from a given correlation model (Market model, Sectorial model, Sectorial Market model and Individual Sectorial model), using a global credit risk factor as the first factor and either VIX (blue line) or MSCI indices (red line) as the second risk factor. 